\title{
Crude phenolic extracts from extra virgin olive oil circumvent de novo breast cancer resistance to HER1/ HER2-targeting drugs by inducing GADD45-sensed cellular stress, G2/M arrest and hyperacetylation of Histone $\mathrm{H3}$
}

\author{
CRISTINA OLIVERAS-FERRAROS ${ }^{1,2^{*}}$, SALVADOR FERNÁNDEZ-ARROYO $^{3 *}$, ALEJANDRO VAZQUEZ-MARTIN ${ }^{1,2^{*}}$ \\ JESÚS LOZANO-SÁNCHEZ ${ }^{3}$, SÍLVIA CUFI ${ }^{1,2}$, JORGE JOVEN ${ }^{4}$, VICENTE MICOL ${ }^{5}$, \\ ALBERTO FERNÁNDEZ-GUTIÉRREZ ${ }^{3}$, ANTONIO SEGURA-CARRETERO ${ }^{3}$ and JAVIER A. MENENDEZ ${ }^{1,2^{*}}$ \\ ${ }^{1}$ Catalan Institute of Oncology (ICO); ${ }^{2}$ Girona Biomedical Research Institute (IdIBGi), Girona, Catalonia; ${ }^{3}$ Department \\ of Analytical Chemistry, Faculty of Sciences, University of Granada, Granada, Andalusia; ${ }^{4}$ Centre de Recerca Biomèdica, \\ Hospital Universitari Sant Joan de Reus, Institut d'Investigació Sanitària Pere Virgili, Universitat Rovira i Virgili, Reus, \\ Catalonia; ${ }^{5}$ Molecular and Cellular Biology Institute (IBMC), Miguel Hernández University, Elche Alicante, Spain
}

Received December 10, 2010; Accepted February 2, 2011

DOI: 10.3892/ijo.2011.993

\begin{abstract}
Characterization of the molecular function of complex phenols naturally present in extra virgin olive oil (EVOO) against the HER2-gene amplified JIMT-1 cell line, a unique breast cancer model that inherently exhibits cross-resistance to multiple HER1/2-targeted drugs including trastuzumab, gefitinib, erlotinib and lapatinib, may underscore innovative cancer molecules with novel therapeutic targets because they should efficiently circumvent de novo resistance to HER1/2 inhibitors in order to elicit tumoricidal effects. We identified pivotal signaling pathways associated with the efficacy of crude phenolic extracts (PEs) obtained from 14 monovarietals of Spanish EVOOs. i) MTT-based cell viability and HPLC coupled to time-of-flight (TOF) mass spectrometry assays revealed that anti-cancer activity of EVOO PEs positively correlated with the phenolic index (i.e., total content of phenolics) and with a higher presence of the complex polyphenols secoiridoids instead of lignans. ii) Genome-wide analyses using $44 \mathrm{~K}$ Agilent's whole human arrays followed by Gene Set Enrichment Analysis (GSEA)-based screening of the Kyoto Encyclopedia of Genes and Genomes (KEGG) pathway database revealed a differential modulation of the JIMT-1 transcriptome at the level of the cell cycle and p53 pathways. EVOO PEs differentially impacted the expression status of stress-sensing, G2-M check-
\end{abstract}

Correspondence to: Dr Javier A. Menendez, Catalan Institute of Oncology, Girona (ICO-Girona) Dr Josep Trueta University Hospital Ctra. França s/n, E-17007 Girona, Catalonia, Spain

E-mail: jmenendez@iconcologia.net; jmenendez@idibgi.org

*Contributed equally

Key words: olive oil, breast cancer, phenolics, GADD45, epigenome, histones point-related GADD45 genes and of p53-related CDKN1A, $C D K N I C$ and $P M A I P-1$ genes. iii) Cell cycle and fluorescence microscopy analyses confirmed that secoiridoid-rich EVOO PE inhibited mitosis to promote G2-M cell cycle arrest. This was accompanied with the appearance of diffuse, even DNA staining with $\gamma \mathrm{H} 2 \mathrm{AX}$ and pan-nuclear hyperacetylation of Histone H3 at Lysine 18. iv) Semi-quantitative Signaling Node Multi-Target ELISAs determined that secoiridoid-rich EVOO PE drastically activated the mitogen-activated protein kinases MEK1 and p38 MAPK, a GADD45-related kinase involved in Histone H3 acetylation. Secoiridoids, a family of complex polyphenols characteristic of Oleaceae plants, appear to permit histones to remain in hyperacetylated states and through the resulting alterations in gene regulation to reduce mitotic viability and metabolic competence of breast cancer cells inherently refractory to HER-targeting therapies ab initio. Oleaceae secoiridoids could provide a valuable phytochemical platform for the design of more pharmacologically active secondgeneration phytopharmaceutical anti-breast cancer molecules with a unique mode of action.

\section{Introduction}

A significant amount of research has been dedicated in the last few years to elucidate the molecular mechanisms that could explain the appearance of acquired resistance to trastuzumab $\left(\right.$ Herceptin $\left.^{\mathrm{TM}}\right)(1-3)$, a recombinant humanized antibody against the HER2 receptor that was the first monoclonal antibody approved for the treatment of a solid tumor by the FDA in 1998 (4-6). Moreover, not all HER2 gene-amplified breast carcinomas respond to treatment with trastuzumab $a b$ initio. Seventy percent of HER2-overexpressing metastatic breast carcinomas show primary resistance to trastuzumab as a single agent and approximately $15 \%$ of women diagnosed with early HER2-positive disease are de novo resistant to trastuzumab and relapse in spite of treatment with trastuzumab-based therapies 
$(7,8)$. In this scenario, unraveling the ultimate responsible underlying de novo resistance to trastuzumab is a major challenge that is beginning to be addressed, and this dilemma is becoming increasingly important as pivotal trials showing clinical benefit of trastuzumab in combination with chemotherapy have led to a new standard of care for women in the adjuvant setting for HER2-overexpressing early-stage breast carcinomas $(9,10)$. Unfortunately, there have been few studies addressing the ultimate molecular mechanisms that could explain de novo resistance to trastuzumab and other HER2-targeted therapies. Because of the lack of appropriate model systems, one can anticipate that this issue could be difficult to study and, accordingly, the precise molecular mechanisms underlying de novo non-sensitivity to trastuzumab remain largely obscure.

It is well established that the identification and the study with high-throughput techniques of phenotypes such as long-term survivors of untreatable malignancies, individuals protected against certain cancer diseases despite having a markedly risk for their development, or cancer patients displaying striking responses following a specific treatment, not only may unveil specific genetic/molecular alterations ultimately causing such characteristic phenotypes but may provide further innovative and clinically valuable therapeutic targets against these disease $(11,12)$. We recently hypothesized that, in a counterintuitive manner, we could take advantage of extreme phenotype selection studies in the identification of clinically relevant molecular features explaining breast cancer resistance to HER2-targeted therapies ab initio. In this regard, intrinsic trastuzumab resistance in a cell line isolated from the pleural fluid of a HER2-positive breast cancer patient with progressive disease on trastuzumab (i.e., JIMT-1) constitutes an excellent scenario to discover alternative explanations for de novo resistance to trastuzumab $(13,14)$. First, high-resolution genomic profiles have confirmed that, among intrinsic breast cancer molecular subtypes $(15,16)$, trastuzumab-sensitive BT-474 and SKBR 3 breast cancer cell lines (two in vitro models widely used as HER2-gene amplified trastuzumab-sensitive breast carcinomas) display a luminal B-like gene expression phenotype whereas trastuzumab-refractory JIMT-1 cells rather exhibit the closest resemblance to the actual HER2-positive gene expression breast cancer subtype (17). Second, JIMT-1 cells provide a valuable experimental model for the studies of resistance to HER-targeted therapies as they are largely insensitive to the growth inhibitory effects of the HER2/HER3 monoclonal antibodies trastuzumab and pertuzumab and to the HER1/HER2 tyrosine kinase inhibitors (TKIs) gefitinib, erlotinib, and lapatinib $(13,14,17)$. Owing to redundant molecular mechanisms such as low levels of HER2 protein expression and activation despite $H E R 2$ gene amplification, loss of the phosphatase and tensin homolog (PTEN) tumor suppressor, activating mutation of the PIK3CA gene, and intrinsic enrichment in the $\mathrm{CD} 44^{\mathrm{pos}} \mathrm{CD} 24^{\text {neg/low }}$ phenotype with stem/progenitor cell properties $(17,18)$, JIMT-1 cell line constitutes a naturallyoccurring 'extreme phenotype' of de novo cross-refractoriness to multiple HER targeting therapies.

Extra virgin olive oil (EVOO)-derived complex polyphenols have been shown to exert significant anti-carcinogenic effects by directly modulating the activities of various types of receptor tyrosine kinases (RTKs), including HER2 (19-22). We here envisioned that, if HER2-positive JIMT-1 breast cancer cells inherently refractory to multiple HER targeting therapies may retain sensitivity to EVOO phenolics, the genetic and functional study of the mode of actions involved may underscore therapeutic targets and innovative drug platforms aimed at circumventing intrinsic resistance to currently available HER targeting drugs. We evaluated the utility of genome-wide expression monitoring combined with functional validation approaches to delineate both the biological actions and the clinical value of complex multi-component phenolic extracts directly obtained from 14 monovarietals of Spanish EVOO. We now reveal for the first time that secoiridoids, a family of complex polyphenols characteristic of Oleaceae plants (23-25), may constitute a phytochemical platform for the development of novel anti-breast cancer drugs with a novel mode of action involving transcriptional activation of stress-responsive GADD45 genes, G2/M cell cycle arrest, activation of the mitogen-activated protein kinases MEK1 and p38 MAPK, and histone acetylation-related chromatin remodeling (26-30). Our current elucidation of a molecular link between administration of complex polyphenols naturally occurring in EVOO and post-translational modification of histones, which can lead to epigenetic regulation of chromatin structure with attendant modulation of cell physiology in response to cellular stress, might suggest a novel antitumor therapeutic strategy able to efficiently circumvent intrinsic refractoriness of HER2-positive breast carcinomas to currently used HER1/2-targeted therapies.

\section{Materials and methods}

Collection of crude phenolic extracts from EVOO monovarietals. Solid phase extraction (SPE) with Diol-cartridges was employed to collect the phenolic fraction of EVOOs from all 14 monovarietals (31).

Quantification of total phenolic compounds. The Folin Ciocalteu method was employed for the quantification of total polyphenols in EVOO crude extracts (32). To calculate the percentage of each family of polyphenols, such as secoiridoids, phenolic alcohols, lignans, flavones and unknowns compounds, the 14 crude EVOO PE were injected into HPLC system (RRLC 1200 series, Agilent Technologies, Santa Clara, CA, USA) coupled to time-of-flight (TOF) mass spectrometer (Bruker Daltonics, Bremen, Germany). The conditions for HPLC and TOF have been described elsewhere (22). The area of each peak was calculated from the extracted ion chromatogram (EIC) by using Data Analysis software provided by Bruker Daltonics. The summation of all areas is the $100 \%$ of phenolic compounds.

Culture conditions. JIMT-1 human breast cancer cell line was established at Tampere University and is available from the German Collection of Microorganisms and Cell Cultures (http://www.dsmz.de/). JIMT-1 cells were grown in DMEM supplemented with $10 \% \mathrm{FBS}$ and $2 \mathrm{mM}$ L-glutamine. Cells were maintained at $37^{\circ} \mathrm{C}$ in a humidified atmosphere of $95 \%$ air and $5 \% \mathrm{CO}_{2}$.

Metabolic status assessment (MTT-based cell viability assays). JIMT-1 cells were seeded at a density of $\sim 3,000$ cells per well in a 96-well plate. The next day, cells were treated with 
concentrations ranging from 0.0 to $0.1 \%(\mathrm{v} / \mathrm{v})$ of the whole crude EVOO-PE dissolved in $1 \mathrm{ml}$ of ethanol (stock solution). An appropriate amount of ethanol (v/v) was added to control cells. After 5 days of treatment (EVOO PE were not renewed during the entire period of culture treatment), cells were incubated with a solution of MTT [3-(4, 5-dimethylthiazol2-yl)-2,5-diphenyltetrazolium bromide; Sigma, St. Louis, MO, USA] at a concentration of $5 \mathrm{mg} / \mathrm{ml}$ for $3 \mathrm{~h}$ at $37^{\circ} \mathrm{C}$. The supernatants were then carefully aspirated, $100 \mu 1$ of DMSO was added to each well, and the plates were agitated to dissolve the crystal product. Absorbances were read at $570 \mathrm{~nm}$ using a multi-well plate reader (Model Anthos Labtec 20101.7 reader). Cell viability effects upon exposure to EVOO-PE were analyzed as percentages of the absorbance obtained in untreated control cells. For each treatment, cell viability was evaluated as a percentage using the following equation: (A570 of treated sample/A570 of untreated sample) x 100. Cell sensitivity to crude EVOO-PE was expressed in terms of the concentration of $\mathrm{PE}(\mathrm{v} / \mathrm{v})$ needed to decrease by $50 \%$ cell viability $\left(\mathrm{IC}_{50}\right.$ value). Since the percentage of control absorbance was considered to be the surviving fraction of cells, the $\mathrm{IC}_{50}$ values were defined as the concentration of EVOO-PE that produced $50 \%$ reduction in control absorbance.

Agilent GeneChip analyses. Total RNA isolated from JIMT-1 cells grown in the absence or presence of $0.001 \%$ (v/v) EVOO $\mathrm{PE}$ for $6 \mathrm{~h}$ was isolated with TRIzol reagent (Invitrogen, Carlsbad, CA, USA), according to the manufacturer's instructions. RNA quantity and quality were determined using the RNA 6000 Nano Assay kit on an Agilent 2100 BioAnalyzer (Agilent Technologies, Palo Alto, CA, USA), as recommended. Agilent Human Whole Genome Microarrays (G4112F), containing 45,220 probes, were then hybridized. Briefly, $500 \mathrm{ng}$ of total RNA from each sample were amplified by Oligo-dT-T7 reverse transcription and labeled by in vitro transcription with T7 RNA polymerase in the presence of Cy5-CTP or Cy3-CTP using the QuickAmp Labeling Kit (Agilent) and purified using RNAeasy columns (Qiagen). After fragmentation, $825 \mathrm{ng}$ of labeled cRNA from each of the two samples were co-hybridized in in situ hybridization buffer (Agilent) for $17 \mathrm{~h}$ at $65^{\circ} \mathrm{C}$ and washed at room temperature (RT) $1 \mathrm{~min}$ in Gene Expression Wash Buffer 1 (Agilent) and $1 \mathrm{~min}$ at $37^{\circ} \mathrm{C}$ in Gene Expression Wash Buffer 2 (Agilent).

Statistical analysis of microarray data. The images were generated on a confocal microarray scanner (G2565BA, Agilent) at $5 \mu \mathrm{m}$ resolution and quantified using GenePix 6.0 (Molecular Dynamics). Spots with signal intensities twice above the local background, not saturated and not flagged by GenePix were considered reliable. Extracted intensities were back-ground-corrected and the $\log 2$ ratios were normalized in an intensity-dependent fashion by the global LOWESS method (intra-chip normalization). Normalized $\log 2$ ratios were scaled between arrays to make all data comparable. Raw data were processed using MMARGE, a web implementation of LIMMA - a microarray analysis library developed within the Bioconductor project in the R statistical environment. To determine genes that were differentially expressed, the multiclass SAM (significance analysis of microarrays) procedure was applied. Probes with q-value
(FDR) $<5 \%$ and additionally a fold change exceeding 1.2 in absolute value were selected as the relevant ones. Microarray probes were collapsed to genes by taking the median $\log 2$ ratio of the respective probes per gene.

Functional analysis of microarray data. To learn more about the biological context of the genes found to be regulated, we applied Gene Set Enrichment Analyses (GSEA). GSEA is a computational method that determines whether an a priori defined set of genes shows statistically significant, concordant differences between two biological states (e.g., phenotypes). Groups of related treatment comparison were built by using EVOO-PE 12 and EVOO-PE 7 as low-and high-responder phenotypes, respectively. Thus, the first group included the following comparisons: EVOO-PE 12 versus EVOO-PE 3, EVOO-PE 12 versus EVOO-PE 7 and EVOO-PE 12 versus EVOO-PE 10. The second group included the following comparisons: EVOO-PE 7 versus EVOO-PE 3, EVOO-PE 10 versus EVOO-PE 7 and EVOO-PE 12 versus EVOO-PE 7. The combination of genes commonly regulated in those comparisons was then used as the list of interesting genes. Enrichment of the interesting genes within all available (i.e., 212) KEGG pathways that contained genes present on the used microarray platform was tested with Fisher's exact test. Pathways with q-value (FDR) $<5 \%$ were considered as significantly enriched.

Cell cycle analysis. Adherent and detached cells were collected after trypsin detachment, washed in phosphate-buffered salt solution (PBS) and centrifuged at $1500 \mathrm{rpm}$. Cells were resuspended at $2 \times 10^{6}$ cells $/ \mathrm{ml}$ in PBS and fixed in ice-cold $80 \%$ ethanol for, at least, $24 \mathrm{~h}$. Fixed cells were centrifuged at $300 \mathrm{x} \mathrm{g}$ and each sample resuspended in propidium iodide (PI) stain buffer $\left(0.1 \%\right.$ Triton X-100 ${ }^{\circledR}, 200 \mu \mathrm{g}$ of DNase-free RNase A, $20 \mu \mathrm{g}$ of PI) in PBS for $30 \mathrm{~min}$. After staining, samples were analyzed using a FACSCalibur (Becton-Dickinson, San Diego, CA, USA) and ModFiT LT (Verity Software).

Immunofluorescence staining and high-content confocal imaging. Cells were seeded at $\sim 5,000$ cells/well in 96-well clear bottom imaging tissue culture plates (Becton-Dickinson Biosciences, San Jose, CA, USA) optimized for automated imaging applications. Triton X-100 permeabilization and blocking, primary antibody staining [phospho-Histone H2A.X (Ser139) 20E3 rabbit mAb \#9718, Cell Signaling Technology, Inc. and Histone H3 modification antibody K18ac, Upstate Biotechnology, Millipore-both diluted according to the procedure suggested by the manufacturer], secondary antibody staining using Alexa Fluor ${ }^{\circledR} 488$ goat anti-rabbit/mouse IgGs (Invitrogen, Molecular Probes, Eugene, OR, USA) and counterstaining (using Hoechst 33258; Invitrogen) were performed following BD Biosciences protocols. Images were captured in different channels for Alexa Fluor 488 (pseudo-colored green) and Hoechst 33258 (pseudo-colored blue) on a BD Pathway ${ }^{\mathrm{TM}} 855$ Bioimager System (Becton-Dickinson) with x20 or x40 objectives (NA 075 Olympus). Merged images were obtained according to the Recommended Assay Procedure using BD Attovision $^{\mathrm{TM}}$ software.

Semi-quantitative determination of AKT, Stat3, p38 MAPK, MEK1 and $N F-\kappa B$ phosphorylation status. CST's PathScan ${ }^{\circledR}$ 

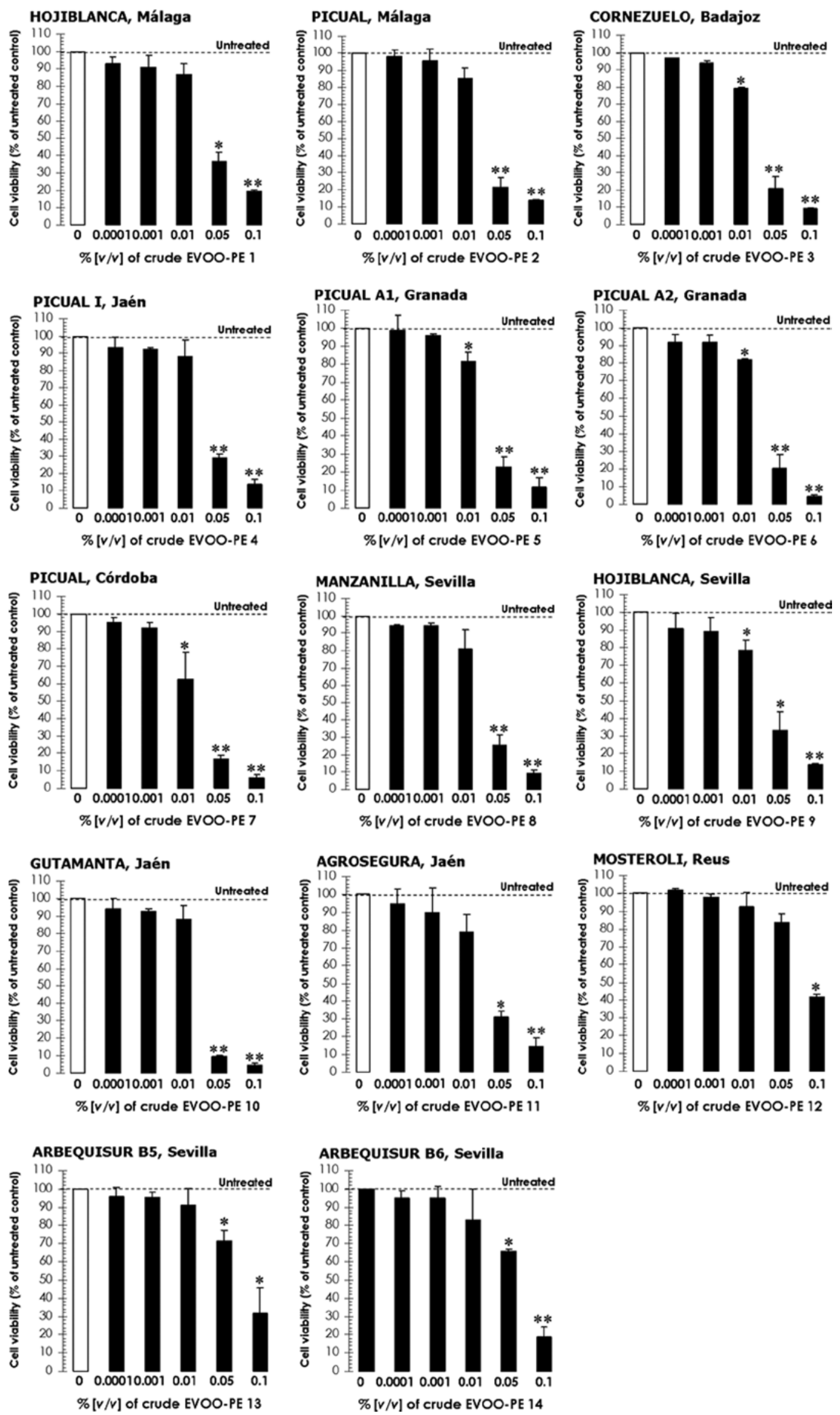

Figure 1. Effects of EVOO-PE on cell viability in JIMT-1 breast cancer cells. The metabolic status of trastuzumab-refractory JIMT-1 treated with graded concentrations of individual EVOO-PE was evaluated using a MTT-based cell viability assays and constructing dose-response graphs as \% of untreated cells (dashed line, $100 \%$ cell viability). Results are means (columns) and 95\% confidence intervals (bars) of three independent experiments made in triplicate. Statistically significant differences (one-factor ANOVA analysis) between experimental conditions and unsupplemented control cells are shown by asterisks $\left({ }^{*} \mathrm{P}<0.01 ;{ }^{*} \mathrm{P}<0.001\right)$. All statistical tests were two-sided. 
Signaling Nodes Multi-Target Sandwich ELISA Kit \#7272 was purchased from Cell Signaling Technology, Inc. This solid phase sandwich enzyme-linked ImmunoSorbent assay combines the reagents necessary to detect endogenous levels of AKT1, phospho-AKT1 (Ser473), phospho-MEK1 (Ser217/221), phospho-p38 MAPK (Thr180/Tyr182), phosphoStat3 (Tyr705) and phospho-NF-kB p65 (Ser536). JIMT-1 cells $(75-80 \%$ confluent) were starved overnight and then cultured in the absence or presence of $0.001 \% \mathrm{v} / \mathrm{v}$ EVOO PE in $5 \% \mathrm{FBS}$-containing culture medium for $48 \mathrm{~h}$. Cells were washed twice with cold-PBS and then lysed in buffer [ $20 \mathrm{mmol} / \mathrm{l}$ Tris $\mathrm{pH} 7.5,150 \mathrm{mmol} / 1 \mathrm{NaCl}, 1 \mathrm{mmol} / 1$ EDTA, $1 \mathrm{mmol} / 1$ EGTA, 1\% Triton X-100, $2.5 \mathrm{mmol} / 1$ sodium pyrophosphate, $1 \mathrm{mmol} / \mathrm{l} \beta$-glycerolphosphate, $1 \mathrm{mmol} / 1 \mathrm{Na}_{3} \mathrm{VO}_{4}, 1 \mu \mathrm{g} / \mathrm{ml}$ leupeptin, $1 \mathrm{mmol} / 1$ phenylmethylsulfonylfluoride, and complete protease inhibitor cocktail (Sigma-Chemicals)] for $30 \mathrm{~min}$ on ice. The lysates were cleared by centrifugation in an Eppendorff tube $\left(15 \mathrm{~min}\right.$ at $\left.14,000 \mathrm{x} \mathrm{g}, 4^{\circ} \mathrm{C}\right)$. Protein content was determined against a standardized control using the Pierce Protein Assay Kit (Rockford, IL). Differential phosphorylation of AKT1, phospho-AKT, phospho-MEK1, phospho-p38 MAPK, phospho-Stat3 and phospho-NF- $\kappa$ B p65 was measured as per the manufacturer's instructions. Briefly, after incubation with cell lysates at a protein concentration of $0.5 \mathrm{mg} / \mathrm{ml}$, the target phospho-protein is captured by the antibody coated onto the microwells. Following extensive washing, a detection antibody is added to detect the captured target phospho-protein. An HRP-linked secondary antibody is then used to recognize the bound detection antibody. The HRP substrate TMB is added to develop color. The magnitude of absorbance (measured at $450 \mathrm{~nm}$ ) for this developed color is proportional to the quantity of bound target protein.

Statistical analyses. Two-group comparisons were performed by the Student's t-test for paired and unpaired values. Comparisons of means of $\geq 3$ groups were performed by ANOVA and the existence of individual differences, in case of significant F-values at ANOVA, tested by Scheffé's multiple contrasts. For correlations between two parameters, the predicted lines were determined by simple linear regression analysis. The P-values and Pearson's linear correlation coefficient (r) were calculated with XLSTAT (Addinsoft ${ }^{\mathrm{TM}}$ ) and $\mathrm{P}<0.001$ was considered to be significant.

\section{Results}

Cell growth inhibitory effects of crude EVOO-PE against JIMT-1 breast cancer cells. To evaluate whether trastuzumabrefractory JIMT-1 cells, concentrations of the anti-HER2 monoclonal antibody trastuzumab as high as $1000 \mu \mathrm{g} / \mathrm{ml}$ failed to significantly alter JIMT-1 cell viability as evaluated by the MTT assay (data not shown), retained sensitivity to crude PE directly obtained from 14 EVOO monovarietals, JIMT-1 cells were cultured in the absence or presence of a series of ethanolic dilutions (i.e., $0 \%, 0.0001,0.001,0.01,0.05$ and $0.1 \% \mathrm{v} / \mathrm{v}$ ), which were prepared immediately before starting each experiment by diluting full strength EVOO-PE (100\%) in fresh culture medium. The highest solvent concentration in the medium $(0.1 \% \mathrm{v} / \mathrm{v}$ ethanol) has no significant effect on the metabolic status of JIMT-1 cells (data not shown). Although
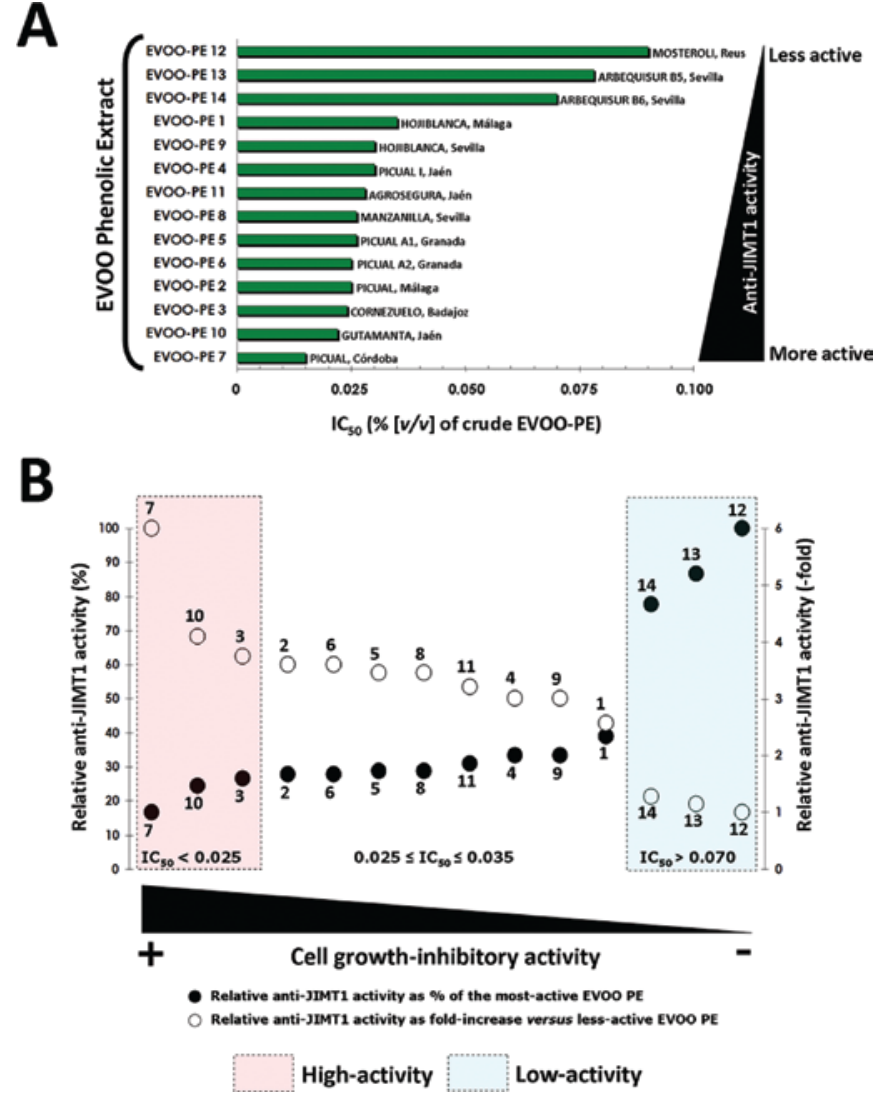

Figure 2. Differential growth-inhibitory efficacy of EVOO-PE against JIMT-1 breast cancer cells. Top, sensitivity of JIMT-1 cells to individual EVOO-PE was expressed in terms of the concentration of $\mathrm{PE}[\%(\mathrm{v} / \mathrm{v})]$ required to decrease by $50 \%\left(\mathrm{IC}_{50}\right)$ cell viability. Since the percentage of control absorbance in MTT-based cell viability assays (Fig. 1) was considered to be the surviving fraction of cells, the EVOO-PE $\mathrm{IC}_{50}$ values were defined as the concentration of $\mathrm{PE}$ that produced $50 \%$ reduction in control absorbance (by interpolation upon construction of dose-response curves). Bottom, comparative efficacy of EVOO-PE against JIMT-1 cells was carried out by arbitrarily normalizing EVOO-PE $\mathrm{IC}_{50}$ values as either $\%$ of the most-active EVOO-PE (EVOO-PE $7=100 \%$ activity) or fold-increases versus less-active EVOO PE (EVOO-PE $12=1.0$-fold change). Statistically significant changes in curves slopes identified three groups of EVOO-PE with similar $\mathrm{IC}_{50}$ values: $1, \mathrm{IC}_{50}<0.025 \% \mathrm{v} / \mathrm{v} ; 2,0.025 \% \mathrm{v} / \mathrm{v} \leq \mathrm{IC}_{50} \leq 0.035 \% \mathrm{v} / \mathrm{v} ; 3, \mathrm{IC}_{50}>0.70 \% \mathrm{v} / \mathrm{v}$.

all the crude EVOO-PE were capable of decreasing JIMT-1 cell viability in a concentration-dependent manner (Fig. 1), we noted remarkable differences in the ability of individual EVOO-PE to elicit growth-inhibitory responses in JIMT-1 cells. Thus, concentrations as low as $0.01 \% \mathrm{v} / \mathrm{v}$ notably decreased cell viability when employing PE obtained from EVOO mono-varietals 3 and 7. Conversely, concentrations as high as $0.1 \% \mathrm{v} / \mathrm{v}$ were needed to significantly decrease cell viability when employing PE obtained from EVOO monovarietals 12,13 and 14 .

To accurately evaluate differences in the JIMT-1 breast cancer cell growth inhibitory activities among EVOO-PE, $\mathrm{IC}_{50}$ values (i.e., the concentration of EVOO-PE needed to decrease cell viability by $50 \%$ relative to untreated control cells) were calculated by interpolation upon construction of dose-response curves. We obtained a wide series of $\mathrm{IC}_{50}$ values ranging from $0.015 \% \mathrm{v} / \mathrm{v}(\mathrm{EVOO}-\mathrm{PE} 7)$ to $0.090 \% \mathrm{v} / \mathrm{v}$ (EVOOPE 12) (Fig. 2, top). Upon this approach, crude EVOO PE exhibited the following cytotoxic potencies: EVOO-PE $7>$ 
Table I. Total phenolic content in EVOO PE and percentage values for each family of polyphenols.

\begin{tabular}{|c|c|c|c|c|c|c|}
\hline & Total phenolic index & Secoiridoids ${ }^{\mathrm{b}}$ & Alcohols ${ }^{\mathrm{b}}$ & Lignans ${ }^{b}$ & Flavones $^{\mathrm{b}}$ & Unknown ${ }^{\mathrm{b}}$ \\
\hline EVOO-PE1 & $206.66 \pm 0.31$ & 88.14 & 3.94 & 1.24 & 5.27 & 1.41 \\
\hline EVOO-PE2 & $242.05 \pm 5.85$ & 91.94 & 4.12 & 0.63 & 2.35 & 0.95 \\
\hline EVOO-PE3 & $229.14 \pm 0.46$ & 93.72 & 1.02 & 0.50 & 2.89 & 1.87 \\
\hline EVOO-PE4 & $220.81 \pm 2.33$ & 90.04 & 5.62 & 0.71 & 2.36 & 1.26 \\
\hline EVOO-PE5 & $208.64 \pm 2.31$ & 92.41 & 3.46 & 0.60 & 2.63 & 0.90 \\
\hline EVOO-PE6 & $244.24 \pm 1.70$ & 92.34 & 3.31 & 0.56 & 2.85 & 0.94 \\
\hline EVOO-PE7 & $302.13 \pm 1.77$ & 94.06 & 2.15 & 0.51 & 2.61 & 0.67 \\
\hline EVOO-PE8 & $314.78 \pm 2.11$ & 90.37 & 2.85 & 0.80 & 4.81 & 1.16 \\
\hline EVOO-PE9 & $292.27 \pm 1.67$ & 87.23 & 2.19 & 1.05 & 8.41 & 1.12 \\
\hline EVOO-PE10 & $252.43 \pm 1.43$ & 93.03 & 1.96 & 0.57 & 3.68 & 0.76 \\
\hline EVOO-PE11 & $285.47 \pm 4.62$ & 89.19 & 4.79 & 0.73 & 4.36 & 0.93 \\
\hline EVOO-PE12 & $82.25 \pm 1.99$ & 64.80 & 2.06 & 13.38 & 14.34 & 5.42 \\
\hline EVOO-PE13 & $142.27 \pm 1.39$ & 80.77 & 1.81 & 6.62 & 7.33 & 3.47 \\
\hline EVOO-PE14 & $140.95 \pm 1.43$ & 81.26 & 1.74 & 7.07 & 6.41 & 3.52 \\
\hline
\end{tabular}

${ }^{a}$ Expressed in ppm of caffeic acid equivalents. ${ }^{b}$ Relative abundance expressed in $\%$.

EVOO-PE $10>$ EVOO-PE $3>$ EVOO-PE $2>$ EVOO-PE $6>$ EVOO-PE $5>$ EVOO-PE $8>$ EVOO-PE $11>$ EVOO-PE $4>$ EVOO-PE $9>$ EVOO-PE $1>$ EVOO-PE $14>$ EVOO-PE $13>$ EVOO-PE 12 (Fig. 2, bottom). Anti-JIMT-1 activity was found to be up to 6-times higher when using EVOO-PE 7 than when using EVOO-PE 12. When JIMT-1 breast cancer cell growthinhibitory potencies of EVOO-PE were arbitrarily normalized as \% of the most-active EVOO-PE as well as fold-increase versus less-active EVOO-PE, curves slopes identified three groups of EVOO-PE with different anti-JIMT-1 behaviors (Fig. 2, bottom). Highly active PE from EVOOs 7 (Picual, Córdoba, Spain), 10 (Gutamanta, Jaén, Spain) and 3 (Cornezuelo, Badajoz, Spain) exhibited $\mathrm{IC}_{50}$ values $<0.025 \%$ v/v. Conversely, less-active PE from EVOOs 14 (Arbequisur B6, Sevilla, Spain), 13 (Arbequisur B5, Sevilla, Spain) and 12 (Mosteroli, Reus, Spain) exhibited $\mathrm{IC}_{50}$ values $>0.070 \% \mathrm{v} / \mathrm{v}$. Most of the EVOO-PE exhibited intermediate $\mathrm{IC}_{50}$ values ranging from 0.025 to $0.035 \% \mathrm{v} / \mathrm{v}$.

Cytotoxic potencies of crude EVOO-PE relate to their relative content on secoiridoids. Table I shows the total phenolic content in individual EVOO monovarietals as assessed by the Folin Ciocalteu method. Table I shows also the percentage of each family of polyphenols in individual EVOO-PE. EVOO-PE appeared to differ little both in the total content and in the relative abundance of the main EVOO phenolic families (i.e., secoiridoids, lignans, flavones, phenolic alcohols), thus suggesting that small alterations in these parameters should significantly impact in the tumoricidal potency of individual EVOO-PE. This notion was supported further when $\mathrm{IC}_{50}$ values for each EVOO-PE were plotted as a function (on a linear-linear scale) of the total phenolic content (Fig. 3A). Second-order polynomial regression analyses suggested a positive correlation between the growth inhibitory potencies of EVOO-PE and their total phenolic content $\left(\mathrm{R}^{2}=0.7804\right)$.
EVOO-PE displaying high phenolic indexes ( $>200$ ppm of caffeic acid equivalents) were significantly more active than those bearing phenolic indexes $<150 \mathrm{ppm}$ of caffeic acid equivalents. An excellent correlation was found between the growth inhibitory potencies of EVOO-PE and their relative content of lignans/secoiridoids families of complex polyphenols (Fig. 3B, top). Whereas exacerbated growth-inhibitory responses positively related to the enrichment of individual EVOO-PE in their relative content of secoiridoid polyphenols, the substitution of secoiridoids by lignans rather related to loss of tumoricidal activity (Fig. 3B, bottom). The correlation between lignans content and growth-inhibitory activity fitted to a polynomial curve, showing an R2 of 0.9155 .

Effects of EVOO-PE on the JIMT-1 transcriptome: genomewide analyses to identify key pathways associated with the degree of anti-tumoral potency among EVOO-PE. In an attempt to understand the existence of gene-based differences in the response of JIMT-1 cells to individual EVOO-PE differentially enriched in complex polyphenols such as secoiridoids and lignans, we employed microarray technology to clarify further the interaction between phenolic compounds with the transcriptome of trastuzumab-refractory HER2-positive JIMT-1 breast cancer cells. We evaluated the ability of individual crude EVOO-PE 7, 10, 3 and 12 to induce global changes in gene expression by using whole human genome microarrays (i.e., Agilent $44 \mathrm{~K}$ Whole Human genome Oligo Microarray containing 45,220 features, probes-representing 41,000 unique human genes and transcripts). RNA was extracted and prepared from JIMT-1 cells that had been cultured for $6 \mathrm{~h}$ at $70 \%$ confluence in the presence or absence of EVOO-PE 7, 10, 3 or $12(0.001 \% \mathrm{v} / \mathrm{v})$. After RNA hybridization to Agilent Technologies Whole Human Genome OligoMicroarrays, normalized and filtered data from all experimental groups were analyzed simultaneously using the significance analysis 
A

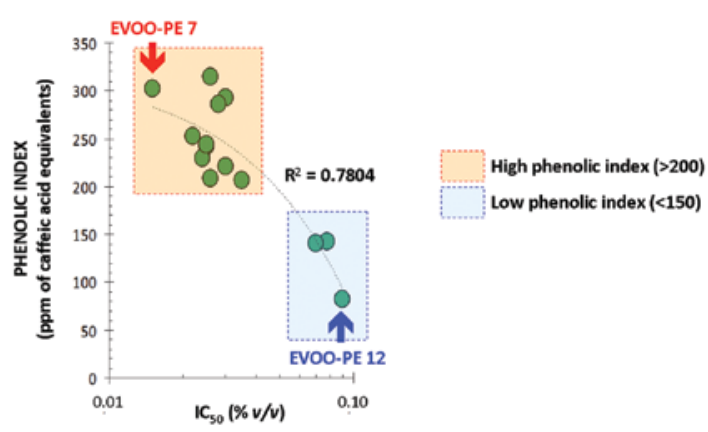

B
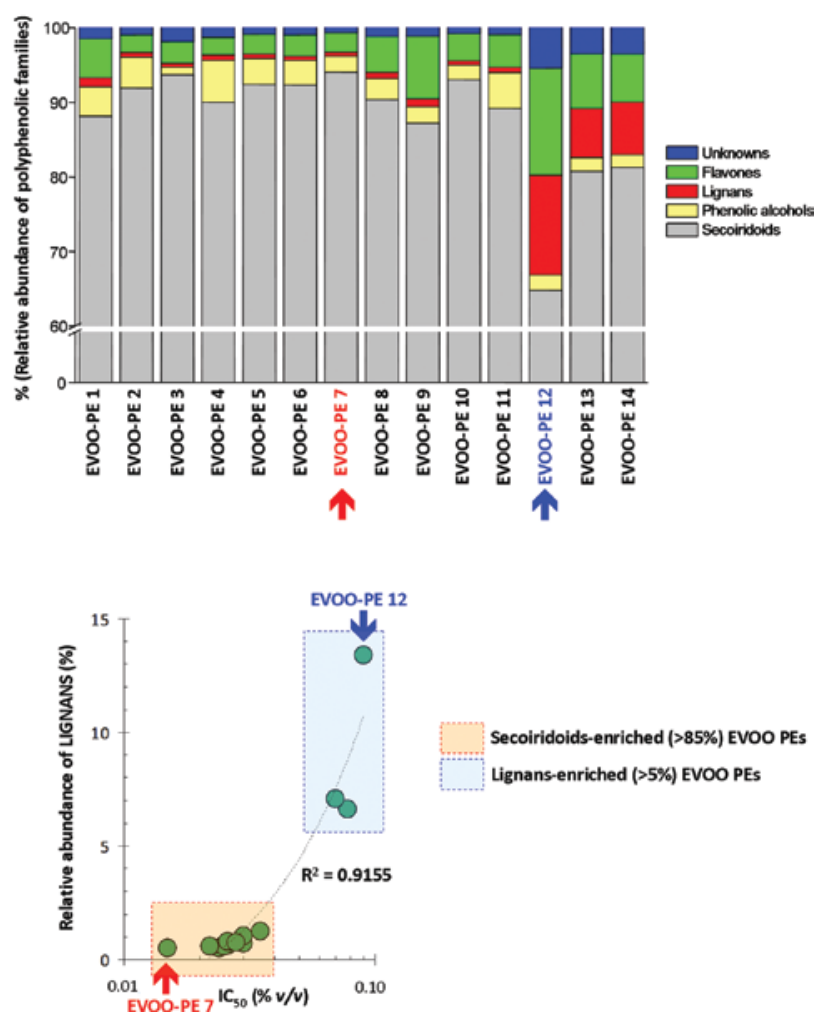

Figure 3. Correlations between chemical composition and growth inhibitory activity of EVOO-PE. Relationships between growth-inhibitory activities (expressed as $\mathrm{IC}_{50}$ values) and either phenol concentrations of EVOO-PE (expressed as ppm of caffeic acid equivalents) (A) or relative abundance of lignans (expressed as \% of total polyphenols) (B, bottom panel) in JIMT-1 cells. Considering the families of phenolic compounds that are naturally present in EVOO and performing the quantification in terms of flavones, lignans, phenolic alcohols and secoiridoids, results in terms of $\%$ of families of phenolic compounds are shown in (B, top panel). Data were expressed on linear rather than $\log$ scales. The obtained data were adjusted to a secondorder polynomial curve ( $\mathrm{R}^{2}$ values are shown).

of microarray (SAM) algorithm. We set the significance cut-off at a median false discovery rate (FDR) of $<5.0 \%$. To determine the specific effects of crude EVOO-PE on gene expression, each treatment group was separately compared with the control group using a 2.0-fold change cut-off.

To identify key pathways/functions potentially associated with the degree of anti-tumoral activity among crude PE isolated from individual EVOO monovarietals, we focused on whole gene (functional) pathways instead of outlier-sum statistic gene groups. We performed this 'gene set' analysis using the Gene Set Enrichment Analysis (GSEA), an algorithm that is oriented to identify sets of functionally related genes and is widely used in the analysis of microarray data. Screening the KEGG (Kyoto Encyclopedia of Genes and Genomes) pathway database by GSEA revealed that the sole enriched gene set responsible for the differential efficacy of secoiridoidsrich versus secoiridoids-low/null EVOO-PE was the cell cycle and p53 signaling pathway (Fig. 4, left panels). Analysis of individual genes within these classes revealed that differential regulation of just few cell cycle-related genes could largely explain the sensitivity of JIMT-1 cells to secoiridoid-rich EVOO-PE when compared to secoiridoids low/null-EVOO-PE. The enrichment of this pathway was driven by a group of genes including CREBBP (CREB binding protein, RSTS - RubinsteinTaybi syndrome), $C D K N 1 A$ (p21, Cip1), $C D K N 1 C$ (p57, Kip2) and PMAIP-1 (Noxa, APR). EVOO-PE 12, EVOO-PE 10 and EVOO-PE 3 failed to upregulate $C D K N 1 A, C D K N 1 C$ and $P M A I P 1$ genes when compared to the up-regulatory effects elicited upon treatment with EVOO-PE 7. Remarkably, EVOO-PE had a dramatic differential impact on the expression of the stress-response family of $G A D D 45$ genes. Whereas EVOO-PE 7 drastically up-regulated the expression of three members of the GADD45 gene family including GADD $45 A$ (4.73-fold-increase), GADD45G (7.15-fold-increase) and $G A D D 45 B$ (11.40-fold-increase), the expression levels of $G A D D 45$ genes were largely unchanged upon treatment with EVOO-PE 12, EVOO-PE 10 and EVOO-PE 3.

Differential effects of secoiridoid-rich EVOO PE in cell cycle progression: activation of the G2/M checkpoint in the absence of DNA damage. Because activation of GGAD45 stress-sensing genes has been demonstrated to play a crucial role in the $\mathrm{G} 2 / \mathrm{M}$ checkpoint in response to DNA damage (26-29) (Fig. 4, right panels), we next examined whether treatment with EVOO-PE did modulate cell cycle progression in JIMT-1 cell cultures (Fig. 5, top panels). Cells were cultured in the absence or presence of trastuzumab, EVOO-PE 12 or EVOO-PE 7 for $24 \mathrm{~h}$. Control (untreated) and treated cells were collected and stained with propidium iodide followed by FACS analysis. Likewise, a significant increase in the $\mathrm{G} 2 / \mathrm{M}$ peak (36\% at $24 \mathrm{~h}$ ) was observed solely when JIMT-1 cells were cultured in the presence of EVOO-PE 7 compared with a $15 \%$ increase in the control group as well as in the presence of either trastuzumab (15\%) or EVOO-PE 12 (14\%). These findings strongly suggest that the differential impact of secoiridoid-rich EVOO-PE 7 in trastuzumab-refractory JIMT-1 cell viability is preceded by an acute arrest at the $\mathrm{G} 2 / \mathrm{M}$ of the cell cycle, which may correlate with a differential activation of a GADD45-mediate G2/M checkpoint.

To evaluate whether the differential ability of secoiridoidrich EVOO-PE 7 to activate the G2/M checkpoint related to a previous induction of DNA damage, we monitored Histone $\mathrm{H} 2 \mathrm{AX}$ phosphorylation in the serine 139 residue, a sensitive marker for DNA double-strand breaks (DSBs). The phosphorylated $\mathrm{H} 2 \mathrm{AX}$, designated as $\gamma \mathrm{H} 2 \mathrm{AX}$, is visible within minutes of the induction of DSBs in the damaged cells as nuclear foci which are thought to serve as a platform for the assembly of protein involved in checkpoint responses and DNA repair or during apoptotic chromatin fragmentation. We failed to observe phosphorylation or alterations in nuclear localization of $\mathrm{H} 2 \mathrm{AX}$ in response to short-term (up to $6 \mathrm{~h}$ ) treatments with EVOO-PE 12 and EVOO-PE 7 (data not shown). Accordingly, 

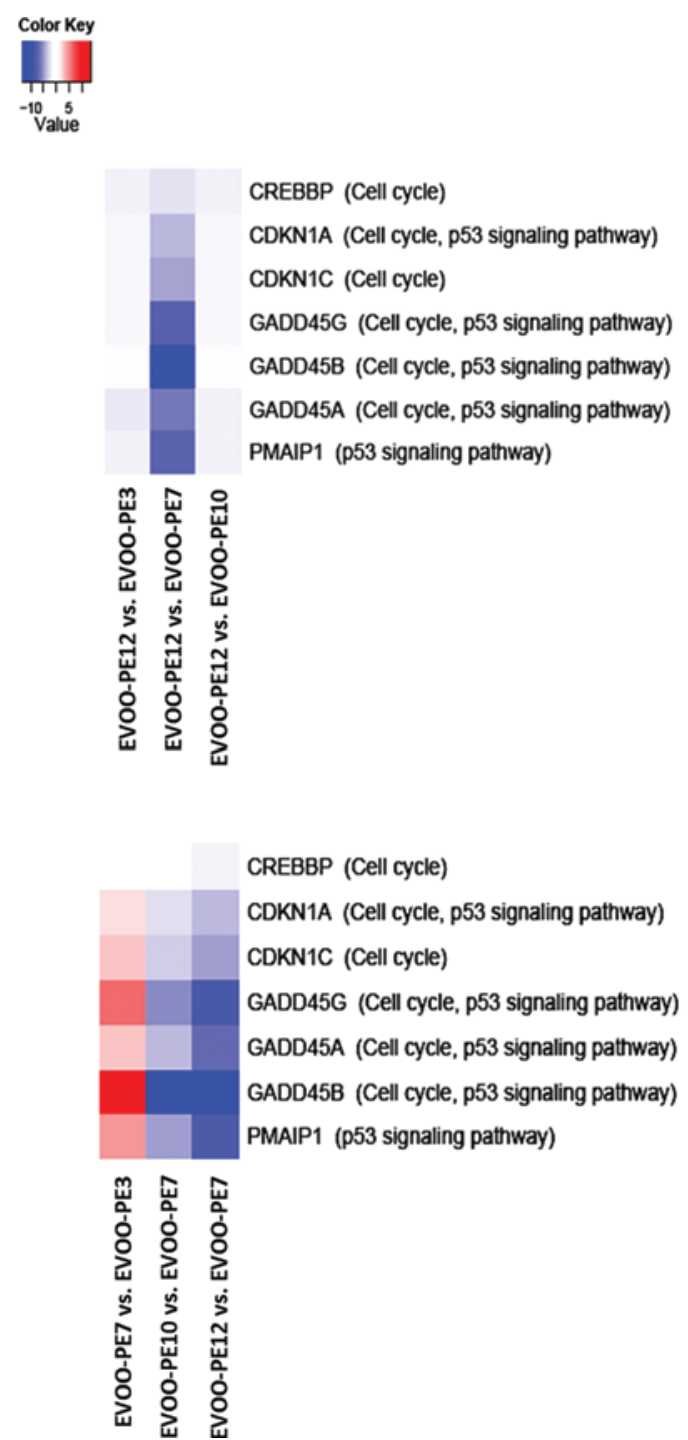

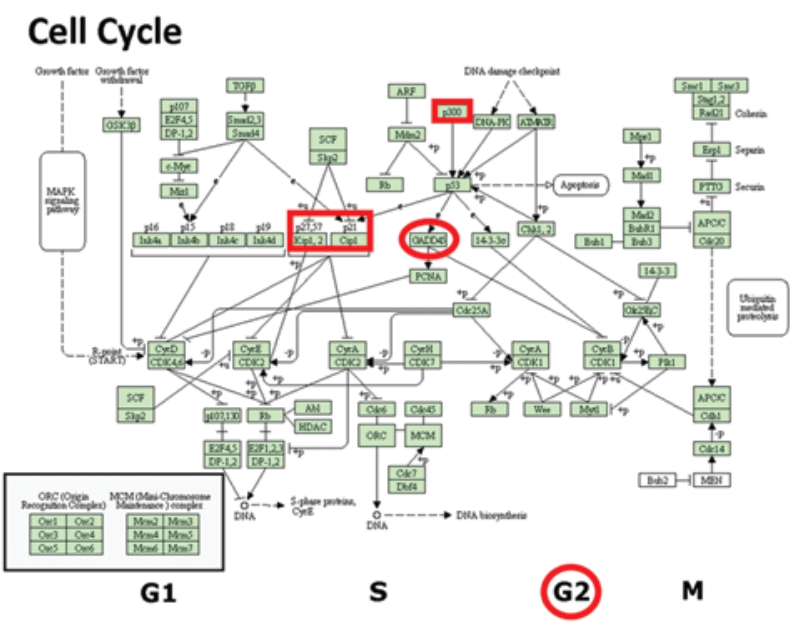

p53 Signaling Pathway

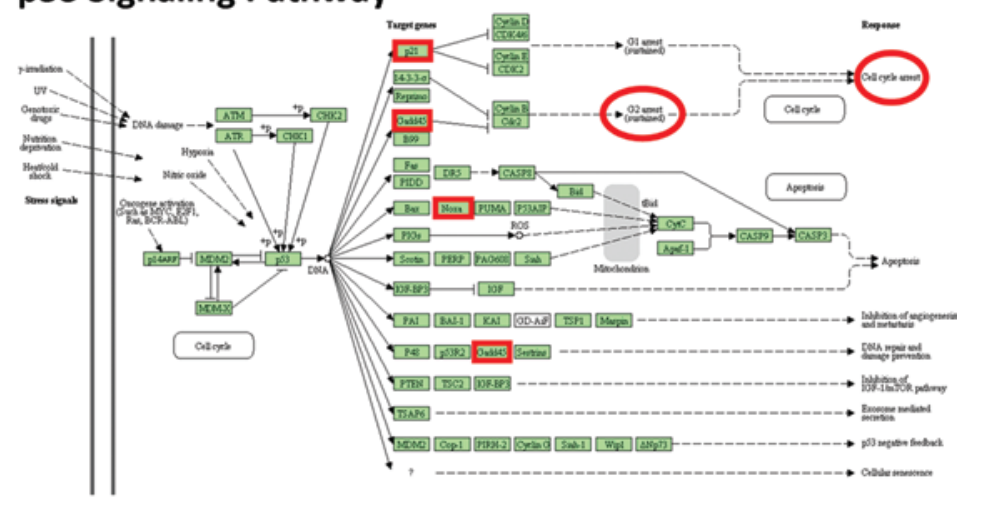

Figure 4. Gene Set Enrichment Analysis (GSEA) of EVOO-PE induced changes in the transcriptome of JIMT-1 cells. Left panels, a heat map showing the genes within the enriched gene set identified by GSEA in the comparative genome-wide analyses of the differential effects of EVOO-PE in the JIMT-1 transcriptome. The colors represent the expression values of the leading edge genes, in which the colors red, pink, light blue, dark blue show the range of expression values from high, moderate, low, to lowest in the comparison. Right diagrams, KEGG pathway maps of cell cycle (top) and p53 signaling pathway (bottom). Genes that were identified in the GSEA analyses (left panels) are shown by colored (red) rectangles.

staining with the vital nuclear stain Hoechst 33258 revealed that long-term exposure ( 24 and $48 \mathrm{~h}$ ) to EVOO-PE 12 and EVOO-PE 7 fails to promote the appearance of apoptotic nuclei and nuclear fragments. Although long-term exposure to EVOO-PE failed also to induce the appearance of discrete $\gamma \mathrm{H} 2 \mathrm{AX}$ foci in JIMT-1 cell nuclei, EVOO-PE notably differed in their ability to induce a diffuse, even, pan-nuclear $\gamma \mathrm{H} 2 \mathrm{AX}$ DNA staining (Fig. 5, bottom panels). In agreement with earlier studies, activation of global $\gamma \mathrm{H} 2 \mathrm{AX}$ DNA staining was observed during mitosis (i.e., maximal $\gamma \mathrm{H} 2 \mathrm{AX}$ occurred at or near metaphase) in untreated (control) and EVOO-PE 12-treated JIMT-1 cell cultures. Intriguingly, a massive pan-nuclear $\gamma \mathrm{H} 2 \mathrm{AX}$ DNA staining was readily apparent in the cell nuclei of JIMT-1 cells cultured in the presence of EVOO-PE 7. These findings suggested that GADD45-related activation of $\mathrm{G} 2 / \mathrm{M}$ checkpoint control in response to secoiridoid-rich EVOO-PE may differ substantially from that induced by DNA damaging agents. This notion was supported further when analyzing changes in the steady-state Histone $\mathrm{H} 3$ acetylation at Lys18 (H3K18). Indirect immunofluorescence using a specific antibody against $\mathrm{AcH} 3 / \mathrm{K} 18$ revealed that, in untreated (control) cells, $\mathrm{H} 3 / \mathrm{K} 18$ became acetylated in the condensed chromosomes of mitotic cells (Fig. 6, top panels). Notably, nuclei in JIMT-1 cells treated with EVOO-PE 7 but not with EVOO-PE 12, were strongly immunoreactive when stained with the specific antibody against anti-AcH3/K18 (Fig. 6, bottom panels), indicating that treatment with secoiridoid-rich EVOO PE successfully induced histone hyperacetylation in cell cycle arrested JIMT-1 cells.

Differential effects of secoiridoid-rich EVOO PE on the activation status of AKT1, MEK1, p38 MAPK, Stat 3 and $N F-\kappa B$. To study further signaling cascades that may be involved in the regulation of $\mathrm{G} 2 / \mathrm{M}$ cell cycle progression in response to the GADD45-sensed cellular stress induced by secoiridoids-rich EVOO PE, we finally assessed the activation 

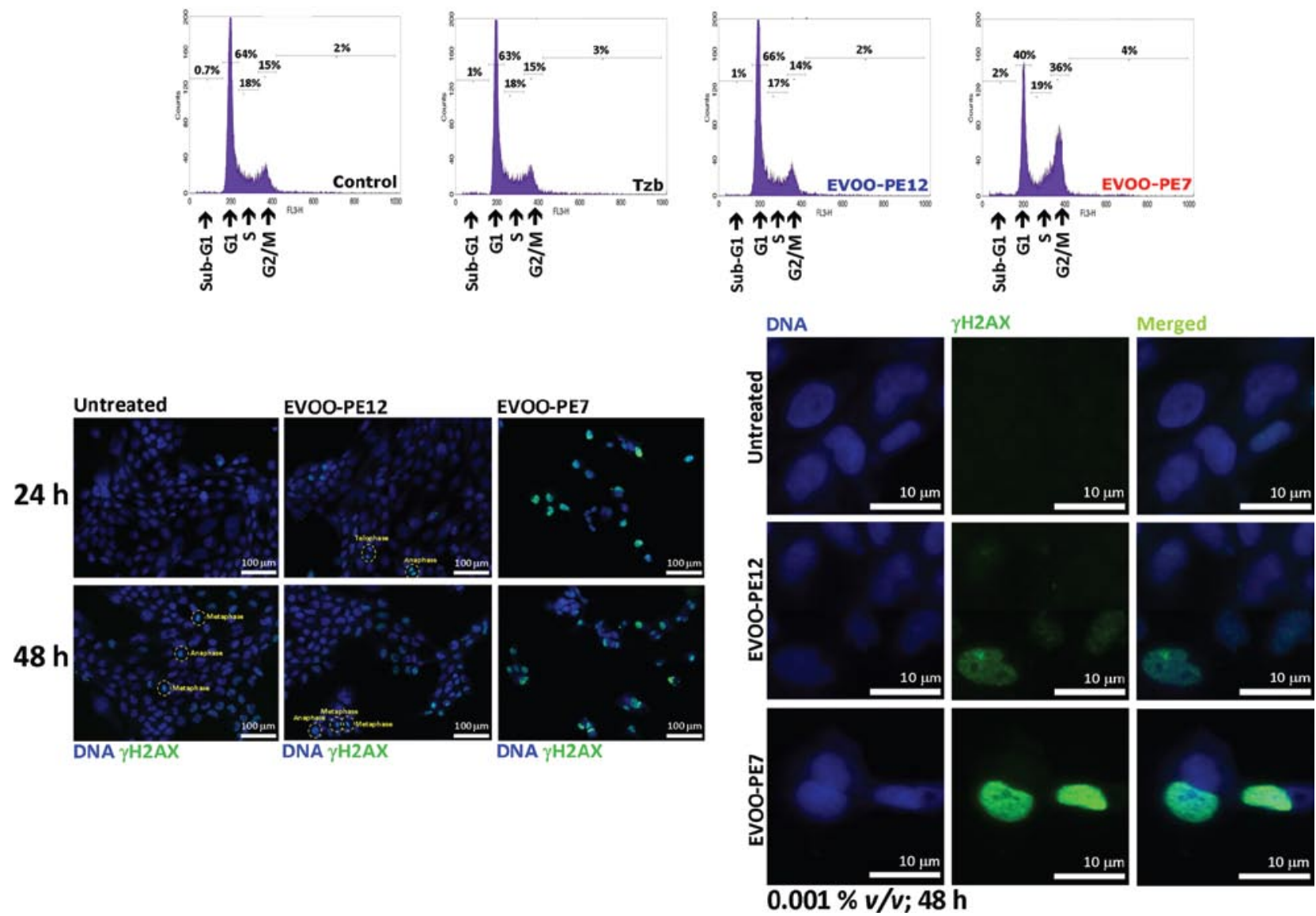

Figure 5. Differential effects of EVOO-PE on cell cycle progression in JIMT-1 breast cancer cells. Top, distribution of JIMT-1 cells in the different cell cycle compartments was analyzed by flow cytometry after $24 \mathrm{~h}$ in the absence or presence of trastuzumab (Tzb, $100 \mu \mathrm{g} / \mathrm{ml})$, EVOO-PE $12(0.001 \% \mathrm{v} / \mathrm{v}) \mathrm{and}$ EVOO-PE $7(0.001 \% \mathrm{v} / \mathrm{v})$, as specified. The panels show representative flow cytometry profiles obtained from three independent experiments. Bottom, immunofluorescence of $\gamma \mathrm{H} 2 \mathrm{AX}$ after exposure to EVOO-PE $12(0.001 \% \mathrm{v} / \mathrm{v})$, EVOO-PE $7(0.001 \% \mathrm{v} / \mathrm{v})$ or mock treatment for 24 or $48 \mathrm{~h}$, as specified Nuclear DNA was counterstained with Hoechst 33258. Images show representative portion of JIMT-1 cell cultures captured in different channels for $\gamma \mathrm{H} 2 \mathrm{AX}$ (green) and Hoechst 33258 (blue) with either x20 (left, montages 2x2) or x40 (right) objectives, and merged on BD Pathway ${ }^{\mathrm{TM}} 855$ Bioimager System using BD Attovision ${ }^{\mathrm{TM}}$ software.

status of convergence points and key regulatory proteins in several signaling pathways controlling cellular events such as growth and differentiation, energy homeostasis and the response to stress and inflammation. We took advantage of the CST's PathScan Signaling Nodes Multi-Target Sandwich ELISA kit, a semi-quantitative technology that combines the reagents necessary to detect endogenous levels of AKT1, phospho-AKT1 (Ser473), phospho-MEK1 (Ser217/221), phospho-p38 MAPK (Thr180/Tyr182), phospho-Stat3 (Tyr705) and phospho-NF- $\mathrm{B}$ p65 (Ser536). Interestingly, the ability of EVOO-PE to inhibit JIMT-1 cell growth and to activate $G A D D 45$ genes closely related to their ability to activate MEK1, p38 MAPK, Stat3, and NF-kB p65 (Fig. 7). EVOO-PE 12, 3, 10 and 7 failed to significantly modulate the activation status of AKT1. Crude PE obtained from secoiridoids-low/null EVOO-PE 12 failed to modulate the phospho-active status of MEK1, p38 MAPK, Stat3, and NF-кB p65. EVOO-PE 3 and EVOO-PE 10 slightly activated, but in a statistically significant manner-MEK 1 (up to 5-fold enhancement), p38 MAPK, and NF-kB p65. Remarkably, secoiridoid-rich EVOOPE7 significantly activated Stat 3 ( 3-fold) and NF-kB p65 ( 6-fold) and dramatically up-regulated up to 20 -and 40 -fold the activation status of MEK1 and p38 MAPK, respectively (Fig. 7).

\section{Discussion}

We are beginning to accumulate epidemiological, clinical and laboratory-based evidence suggesting that consumption of phenolic-enriched fruits, vegetables and herbs might reduce the risk of chronic diseases including human malignancies (33-35). In this regard, it has been repeatedly suggested that the ability of the so-called 'Mediterranean diet' (MD) (i.e., the dietary patterns found in olive-growing areas of the Mediterranean basin) to significantly reduce the risk of several types of human carcinomas including breast cancer (36-39), can be largely attributed to the unique healthy characteristics of EVOO, an integral ingredient of the traditional MD. Although these findings might suggest that, in the future, the use of supplements derived from EVOO will be a useful strategy for the prevention and/or treatment of cancer, both the specific components and the specific molecular mechanisms that exert EVOO-related anti-carcinogenic effects have not yet been thoroughly elucidated. Apart from the health benefits that can be expected from EVOO as the richest source of the monounsaturated fatty acid (MUFA) oleic acid (OA; 18:1n-9) (40), $1-2 \%$ of cold-pressed EVOO (i.e., the juice obtained from the olive fruit solely by mechanical means, without further treatment other than washing, filtration, decantation or centrifugation) 

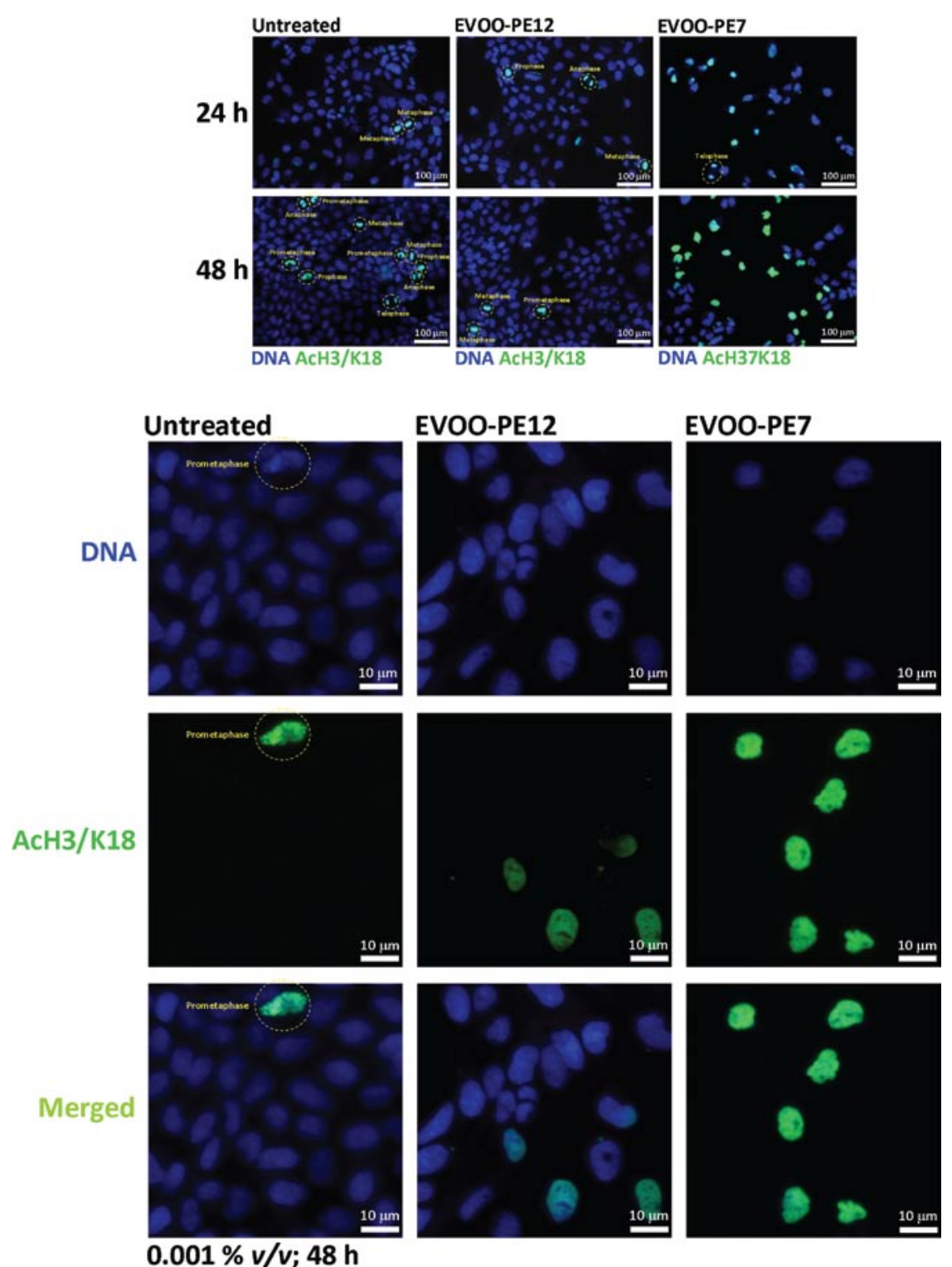

Figure 6. Differential effects of EVOO PE on the acetylation status of Histone H3 in JIMT-1 breast cancer cells. Immunofluorescence of AcH3/K18 after exposure to EVOO-PE $12(0.001 \% \mathrm{v} / \mathrm{v})$, EVOO-PE $7(0.001 \% \mathrm{v} / \mathrm{v})$ or mock treatment for 24 or $48 \mathrm{~h}$, as specified. Nuclear DNA was counterstained with Hoechst 33258. Images show representative portion of JIMT-1 cell cultures captured in different channels for $\gamma \mathrm{H} 2 \mathrm{AX}$ (green) and Hoechst 33258 (blue) with either $\mathrm{x} 20$ (top; montages 2x2) or x40 (bottom) objectives, and merged on BD Pathway 855 Bioimager System using BD Attovision software.

include minor components such as aliphatic and triterpenic alcohols, sterols, hydrocarbons, volatile compounds and several antioxidants (41-47). Although tocopherols and carotenes are also present, hydrophilic phenolics represent the most abundant family of bioactive EVOO compounds. As for many plant-derived phenolics, it has been largely assumed that EVOO-derived complex phenols such as secoiridoids (that include aglycone derivatives of oleuropein, dimethyloleuropein and ligstroside, which are also present in olive fruit) and lignans [such as (+)-pinoresinol and 1-(+)-acetoxypinoresinol] provide health benefits mainly because of their antioxidant activity (48-50). However, the antioxidant capacity of polyphenols does not directly correlate with their efficacy in terms of anticancer activity. Moreover, plasma concentrations of EVOO polyphenols when provided in the diet are often far lower than the levels required for protection against oxidation. It could be argued that metabolites of EVOO polyphenols can reach several times higher concentrations in the bloodstream. These EVOO-derived compounds, however, tend to have a decreased antioxidant activity compared to parent compound $(51,52)$.

Alternatively to general mechanisms largely related to the antioxidant and/or trapping activity of oxygen radicals commonly observed in many plant-derived phenolics, recent studies have demonstrated that complex polyphenols can exert an anti-carcinogenic effect by directly modulating the activities of various types of receptor tyrosine kinases (RTKs) including several members of the HER family (53-58). Results from our own laboratory support the notion that EVOO-derived complex polyphenols may constitute a previously unrecognized family of clinically valuable anti-cancer phytochemicals that significantly affect breast cancer cell proliferation and survival through a molecular mechanism involving the specific suppression of the activity, expression and signal transduction events of the Type I RTK HER2 (19-21). Similarly, trastuzumab- 

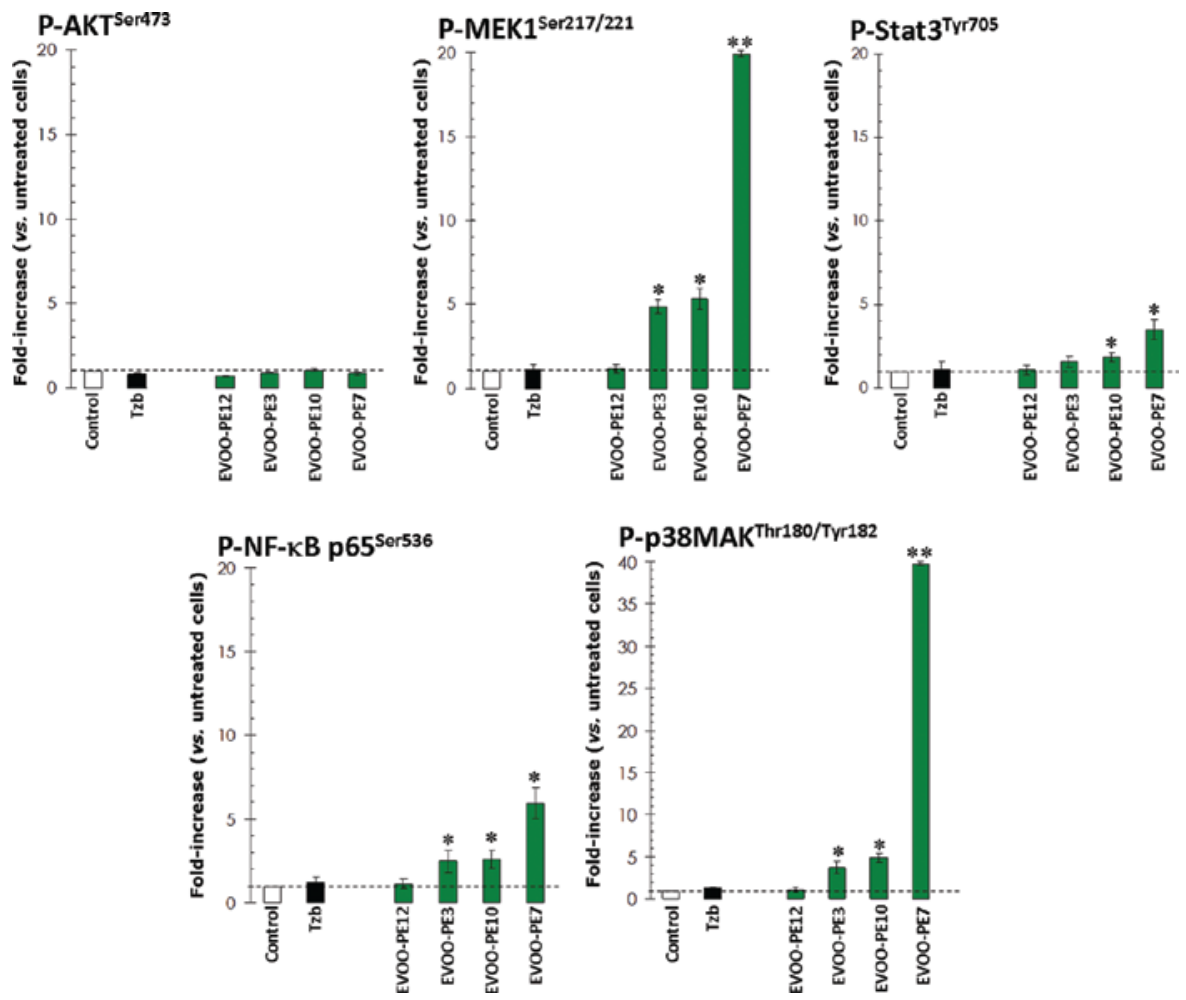

Figure 7. Effects of EVOO-PE on phospho-endogenous levels of AKT, MEK1, p38 MAPK, Stat3 and NF-кB p65 in JIMT-1 breast cancer cells. Cultures of JIMT-1 cells (75-80\% confluent) were starved overnight and treated with either trastuzumab (Tzb, $100 \mu \mathrm{g} / \mathrm{ml}$ ) or 0.001\% v/v of EVOO-PE 12, EVOO-PE 13, EVOO-PE 10 and EVOO-PE 7 for $48 \mathrm{~h}$, as specified. Lysates were assayed at a protein of $0.5 \mathrm{mg} / \mathrm{ml}$ using the PathScan Signaling Nodes Multi-Target Sandwich ELISA Kit \#7272 (Cell Signaling Technology, Inc.) as per the manufacturer's instructions. The absorbance readings at $450 \mathrm{~nm}$ were normalized to those obtained in untreated control cells cultured strictly in parallel. Results are means (columns) and 95\% confidence intervals (bars) of two independent experiments made in duplicate. Statistically significant differences (one-factor ANOVA analysis) between experimental conditions and unsupplemented control cells are shown by asterisks ( $\left.\mathrm{P}<0.01 ;{ }^{*} \mathrm{P}<0.001\right)$. All statistical tests were two-sided.

induced HER2 internalization and down-regulation are thought to be causally related to the mechanism of action of the antibody $(59,60)$. However, we are lacking formal proof for the hypothesis that knockdown of HER2 is sufficient to elicit anti-proliferative effects in HER2-positive tumor cells. In JIMT-1 breast cancer cells, a line recently established from a trastuzumab-resistant breast cancer patient that retains HER 2 gene amplification/ HER2 protein overexpression as well as trastuzumab resistance as a stable phenotype, HER 2 protein is internalized and downregulated by trastuzumab treatment to an extent similar to that observed in trastuzumab-sensitive breast cancer cell lines $(13,14,17,18)$. The very low level of HER 2 TK activity in cultured JIMT-1 implies that trastuzumab-induced HER2 down-regulation does not result in a decreased activation state of key signaling transduction pathways and, therefore, HER2 protein is a 'molecular fossil' that is not required for survival/proliferation of JIMT-1 cells $(13,14,61)$. The ability of EVOO phenolics to suppress HER2 protein expression while eliciting significant growth inhibitory activities against JIMT-1 cells would imply that, in addition to promoting HER2 inhibition, they efficiently circumvent de novo trastuzumab resistance by affecting HER2 downstream specific signaling pathways.

EVOO-derived phenolics with strong anti-JIMT-1 activity may underscore innovative cancer molecules with novel therapeutic targets because, in order to elicit tumoricidal effects, they should affect the expression and/or activity of genes and transduction cascades closely involved in enhanced cancer cell survival. To test this hypothesis, we first obtained crude PE naturally bearing different amounts of phenolic families from 14 Spanish EVOO monovarietals. Although structural diversity and solubility generally impose a significant challenge in the extraction and analysis of phenolics (i.e., some reports estimate that approximately $30 \%$ of the errors in analytical measurements come from the sample preparation step), we were able to accurately estimate the relative levels of the phenolic compounds in individual EVOO-PE. Indeed, our current findings support the notion that high recoveries of EVOO-derived phenolic fractions and good analytical measurements can be obtained by using SPE with Diolcartridges (31). We took advantage of a rapid resolution liquid chromatography method coupled to diode-array and time of flight mass spectrometry (TOF) recently developed in our laboratory to characterize and quantify phenolic compounds in EVOO monovarietals (22). The approach we adopted allows good peak resolutions to identify at least 19 different phenols in less than $20 \mathrm{~min}$. Folin Ciocalteau-based quantification of total phenolics followed by identification of the relative abundance of the main EVOO phenolic families (i.e., secoiridoids, lignans, flavones, phenolic alcohols and other compounds yet unknown) and MTT-based cell viability assays revealed that trastuzumabrefractory JIMT-1 cells likewise retained an exquisite sensitivity to the cytotoxic effects elicited by increasing volumes of crude EVOO PE. More importantly, we described the occurrence of 
correlations between the intrinsic phenolic composition of EVOO-derived crude PE and their anti-proliferative abilities toward JIMT-1 cells. When compared with lignan-rich EVOO-PE, secoiridoid-rich EVOO-PE had a significantly stronger ability (up to 6-times higher) to negatively affect the metabolic status of JIMT-1 breast cancer cells. In this scenario, we sought to identify possible molecular mediators by interrogating the transcriptome of JIMT-1 cells cultured in the absence or presence of poor- and highly active-crude EVOO-PE. Both the duration of EVOO-PE treatment $(6 \mathrm{~h})$ and the low concentration of EVOO PE $(0.001 \% \mathrm{v} / \mathrm{v})$ were chosen to identify the earliest transcriptional events induced by treatment with EVOO-PE, to minimize the detection of gene expression changes due to apoptosis and, therefore, to identify gene expression changes that preceded, and possibly contributed to, the biological effects of EVOO-PE treatments on JIMT-1 cells. When we examined whether differentially expressed genes, which had disparate biological functions, were part of one or more signal transduction pathways, GSEA-based screening of the KEGG pathway database concluded that EVOO-PE differentially modulated breast cancer transcriptome at the level of the cell cycle pathway, with a remarkable up-regulatory impact in G2/M checkpoint-related stress sensor GADD45 genes. Likewise, our results confirmed that gene induction of all three GADD45 isoforms inhibited mitosis and promoted G2/M cell cycle arrest during (moderate) cellular stress imposed by highly active, secoiridoid-rich EVOO-PE (i.e., EVOO-PE 7). Further analyses, at higher concentrations of secoiridoid-rich EVOO-PE and later timepoints, indicated that the mitotic population was preferentially lost from the culture, an effect that correlated with the appearance of a sub-G1 apoptotic peak on the FACScan (data not shown). These results may be consistent with the suggestion that mitotic cells are particularly sensitive to the cytotoxic effects of the secoiridoid-rich EVOO-PE 7.

Secoiridoid-rich EVOO PE7-induced activation of the GADD45 sensing machinery ultimately led to a selective induction of genes related to cell cycle arrest and apoptosis including CDKN1A (p21 $\left.{ }^{\text {Wafl/Cipl }}\right)$ and CDKNIC (p57 $7^{\text {Kip2}}$ ), two powerful inhibitors of cyclin-dependent kinases $(62,63)$, and PMAIP-1 (phorbol-12-myristate-13-acetate-induced protein 1; NOXA, APR) - a tumor suppressor gene that is crucial in fine-tuning p53-related cell death decisions $(64,65)$. The ability of the secoiridoid-rich EVOO-PE 7 to functionally restore the p53 pathway in p53-deficient JIMT-1 cells (13) while efficiently activating the G2/M checkpoint might suggest that natural phenolic molecules from EVOO might unexpectedly function as regulators of histone deacetylase (HDAC) activity. Although future studies appear necessary to definitely elucidate these putative intriguing mechanisms, it should be noted that secoiridoid-rich EVOO-PE 7 appeared to recapitulate wellknown effects of HDAC inhibitors (30,66-68). Supporting this notion, treatment with the secoiridoid-rich EVOO-PE 7 markedly induced the expression of acetylated $\mathrm{H} 3$ histone proteins. Because we confirmed also that the secoiridoid-rich EVOO-PE 7 increased the cell cycle-regulated steady-state phosphorylation status of histone $\mathrm{H} 2 \mathrm{AX}$ but they did not work as exogenous sources of significant DNA damage, breast cancer cell growth inhibitory activities observed upon exogenous supplementation with EVOO-derived complex polyphenols may relate to their differentially ability to regulate gene expression and chromatin structure at the epigenetic level. HDAC inhibitors elicit histones to remain in an acetylated state, and through the resulting alterations in gene expression and chromatin structure, they cause a marked decrease in the viability of cancer cells that associate with a cell-cycle arrest at $\mathrm{G} 2 / \mathrm{M}$ and transcriptional reactivation of dormant tumorsuppressor genes, such as cyclin-dependent kinase inhibitors (CKIs) belonging to the Cip/Kip family (e.g., p21 ${ }^{\text {Wafl/Cip1 }}$ and p57 ${ }^{\text {Kip2 } 2}$ (69-71). EVOO-PE-derived phenolics, by inhibiting HDAC activity and promoting increased acetylation of histones, can cause recruitment of transcription factors that might act as critical regulators of cell cycle and phenotype by influencing contemporaneously several CKI genes. Moreover, a previously unrecognized ability of EVOO phenolics to work as powerful inductors of acetylation of histones to restore the expression of growth-inhibitory tumor-suppressor genes (which had generally been silenced by hypo-acetylation during tumorigenesis) does not preclude a previously described ability of EVOO phenolics to inhibit HER2 activity and expression (19-21). By incorporating HDAC inhibitory functionality into the pharmacophore of the HER1 (EGFR) and HER2 inhibitors, Cai et al (72) recently synthesized a novel series of compounds with potent, multiacting HDAC, HER1, and HER2 inhibitory activities. Based on their findings showing that a compound simultaneously inhibiting HDAC, HER1, and HER2 displayed greater antiproliferative potencies that HDAC inhibitors (i.e., vorinostat), EGFR inhibitors (i.e., erlotinib), HER2 inhibitors (i.e., lapatinib) and combinations of vorinostat with erlotinib/lapatinib, the author suggested that potent multi-acting HDAC, HER1, and HER2 inhibitors may offer greater therapeutic benefits in cancer over single-acting agents through the interference with multiple pathways and potential synergy among HDAC and HER1/HER2 inhibitors (73). In this scenario, our current findings warrant forthcoming studies aimed to analyze structure-activity (SAR) relationships evaluating individual EVOO-derived phenolic candidates in HER kinase activity assays as well as HDAC enzyme assays. Indeed, we cannot exclude the possibility that previously described anti-HER2 effects of EVOO polyphenols due to proteasomal degradation of HER 2 protein (21) might include indirect effects by interacting with chaperone (e.g., HSP90) function as is seen with HDAC inhibition (74). Moreover, induction of G2/M arrest in JIMT-1 cells treated with the secoiridoid-rich EVOO-PE 7 occurred in parallel with a dramatic overactivation of p38 activity. This finding agrees with several reports demonstrating a functional link between stress-activated mitogen-activated protein kinase pathways and GADD45 $(26,27,75,76)$. In this regard, and given that not only the $\mathrm{p} 38$ pathway promotes $\mathrm{G} 2 / \mathrm{M}$ arrest via GADD45 induction in response to cellular stressors such as polyphenolic flavonoids (77) but also that P38 activity depends on MEKK4 activation mediated by each of the three GADD45 proteins in response to a variety of stimuli $(76,78,79)$, it is reasonable to suggest that an autoregulatory loop consisting of mitogen-activated protein pathways, GADD45 protein and cyclin-dependent kinase inhibitors appears to largely coordinate induction of G2/M arrest versus apoptosis in dependence of the nature of EVOO polyphenols and amplitude of cellular stress effects. Moreover, p38 MAPK activity regulates chromatin remodeling via Histone $\mathrm{H} 3$ acetylation $(80,81)$, a regulatory 
role where this MAP kinase controls acetylation by regulating acetyltransferase activity of p300/CBP(82-84), a transcriptional coactivator encoded by $C R E B B P$, one of the genes differentially upregulated in response to secoiridoid-rich EVOO-PE. In the cellular response to secoiridoid-rich EVOO-PE, GADD45 cross-regulated p38 signaling might therefore participate in the recruitment of co-activators with hystone acetyltransferase activity thus directly contributing to the acetylation of histones leading to the activation and transcription of tumor suppressor genes (e.g., p21 ${ }^{\text {Waf1/Cip1 }}$ and p57 ${ }^{\text {Kip2}}$ ) with cell cycle suppressor activity.

As used in the present study, genomic data analyses of microarray technology in association with a functional validation approach could serve as a framework to identify EVOO-derived bioactive phenolics with novel anti-cancer therapeutic effects and clarify the molecular roles of structurally-related complex polyphenols (e.g., lignans, secoiridoids) in the physiological activity of crude PE directly obtained from EVOO (85). Our current findings therefore support the notion that high-throughput experimentation combining massive databases of genomic/ proteomic data with efficient separation methods and powerful spectrometric methods for identification and structure elucidation can be used to obtain chemically standardized multi-component extracts simultaneously acting on multiple targets (86). Importantly, we here confirm that a broad repertoire of chemical entities (e.g., EVOO-derived polyphenols) can act together on multiple targets to differentially activate (e.g., lignan-rich versus secoiridoids-rich EVOO-PE) defense, protective and repair epigenetic mechanisms rather than blocking a sole disease-causing molecular target (e.g., HER2 oncogene). From a molecular perspective, the ability of some secoiridoid-rich EVOO PE to permit histones to remain in hyperacetylated states and through the resulting alterations in gene regulation to inhibit cell cycle progression and to cause a marked decrease in the viability of cancer cells may herald a previously unrecognized epigenetic antitumor therapeutic strategy based on complex polyphenols naturally occurring in EVOO. From a clinical perspective, the identification of a GADD45-sensed, p38 MAPK-related cell growth inhibitory pathway in HER2 gene-amplified JIMT-1 cells molecularly bypasses an impediment to current HER1/2-targeted therapies and provides new targets for future therapeutic management of highly-aggressive basal-like/HER2-positive tumors with refractoriness to trastuzumab and/or lapatinib ab initio $(18,87)$.

\section{Acknowledgments}

Javier A. Menendez is supported in part by the Instituto de Salud Carlos III (Ministerio de Sanidad y Consumo, Fondo de Investigación Sanitaria (FIS), Spain, Grants CP05-00090 and PI06-0778 and RD06-0020-0028), the Fundación Científica de la Asociación Española Contra el Cáncer (AECC, Spain), and by the Ministerio de Ciencia e Innovación (SAF2009-11579, Plan Nacional de I+D+I, MICINN, Spain). Alejandro VazquezMartin is the recipient of a 'Sara Borrell' post-doctoral contract (CD08/00283, Ministerio de Sanidad y Consumo, Fondo de Investigación Sanitaria (FIS), Spain. Sílvia Cufí is the recipient of a Research Fellowship (Formación de Personal Investigador, FPI) by the Ministerio de Ciencia e Innovación (MICINN, Spain). Antonio Segura-Carretero is supported in part by the
Spanish Ministry of Education and Science (Grant AGL200805108-C03-03) and the Andalusian Regional Government Council of Innovation and Science (Grants P07AGR-02619 and P09-CTS-4564).

\section{References}

1. Nahta R and Esteva FJ: Herceptin: mechanisms of action and resistance. Cancer Lett 232: 123-138, 2006.

2. Nahta R, Yu D, Hung MC, Hortobagyi GN and Esteva FJ: Mechanisms of disease: understanding resistance to HER2targeted therapy in human breast cancer. Nat Clin Pract Oncol 3: 269-280, 2006.

3. Nahta R and Esteva FJ: HER2 therapy: molecular mechanisms of trastuzumab resistance. Breast Cancer Res 8: 215, 2006.

4. Pegram MD, Lipton A, Hayes DF, Weber BL, Baselga JM, Tripathy D, Baly D, Baughman SA, Twaddell T, Glaspy JA and Slamon DJ: Phase II study of receptor-enhanced chemosensitivity using recombinant humanized anti-p185HER2/neu monoclonal antibody plus cisplatin in patients with HER2/neuoverexpressing metastatic breast cancer refractory to chemotherapy treatment. J Clin Oncol 16: 2659-2671, 1998.

5. Baselga J, Norton L, Albanell J, Kim YM and Mendelsohn J: Recombinant humanized anti-HER2 antibody (Herceptin) enhances the antitumor activity of paclitaxel and doxorubicin against HER2/neu overexpressing human breast cancer xenografts. Cancer Res 58: 2825-2831, 1998.

6. Nass SJ, Hahm HA and Davidson NE: Breast cancer biology blossoms in the clinic. Nat Med 4: 761-762, 1998.

7. Spector NL and Blackwell KL: Understanding the mechanisms behind trastuzumab therapy for human epidermal growth factor receptor 2-positive breast cancer. J Clin Oncol 27: 5838-5847, 2009.

8. Esteva FJ, Yu D, Hung MC and Hortobagyi GN: Molecular predictors of response to trastuzumab and lapatinib in breast cancer. Nat Rev Clin Oncol 7: 98-107, 2010.

9. Hortobagyi GN: Trastuzumab in the treatment of breast cancer. N Engl J Med 353: 1734-1736, 2005.

10. Gonzalez-Angulo AM, Hortobágyi GN and Esteva FJ: Adjuvant therapy with trastuzumab for HER-2/neu-positive breast cancer. Oncologist 11: 857-867, 2006.

11. Perez-Gracia JL, Gloria Ruiz-Ilundain M, Garcia-Ribas I and Maria Carrasco E: The role of extreme phenotype selection studies in the identification of clinically relevant genotypes in cancer research. Cancer 95: 1605-1610, 2002.

12. Pérez-Gracia JL, Gúrpide A, Ruiz-Ilundain MG, Alfaro Alegría C, Colomer R, García-Foncillas J and Melero Bermejo I: Selection of extreme phenotypes: the role of clinical observation in translational research. Clin Transl Oncol 12: 174-180, 2010.

13. Tanner M, Kapanen AI, Junttila T, Raheem O, Grenman S, Elo J, Elenius $\mathrm{K}$ and Isola $\mathrm{J}$ : Characterization of a novel cell line established from a patient with Herceptinresistant breast cancer. Mol Cancer Ther 3: 1585-1592, 2004.

14. Nagy P, Friedländer E, Tanner M, Kapanen AI, Carraway KL, Isola J and Jovin TM: Decreased accessibility and lack of activation of ErbB2 in JIMT-1, a herceptin-resistant, MUC4-expressing breast cancer cell line. Cancer Res 65: 473-482, 2005.

15. Perou CM, Sørlie T, Eisen MB, van de Rijn M, Jeffrey SS, Rees CA, Pollack JR, Ross DT, Johnsen H, Akslen LA, Fluge O, Pergamenschikov A, Williams C, Zhu SX, Lønning PE, Børresen-Dale AL, Brown PO and Botstein D: Molecular portraits of human breast tumours. Nature 406: 747-752, 2000.

16. Sorlie T, Tibshirani R, Parker J, Hastie T, Marron JS, Nobel A, Deng S, Johnsen H, Pesich R, Geisler S, Demeter J, Perou CM, Lønning PE, Brown PO, Børresen-Dale AL and Botstein D: Repeated observation of breast tumor subtypes in independent gene expression data sets. Proc Natl Acad Sci USA 100: 8418-8423, 2003.

17. Köninki K, Barok M, Tanner M, Staff S, Pitkänen J, Hemmilä P, Ilvesaro J and Isola J: Multiple molecular mechanisms underlying trastuzumab and lapatinib resistance in JIMT-1 breast cancer cells. Cancer Lett 294: 211-219, 2010.

18. Oliveras-Ferraros C, Vazquez-Martin A, Martin-Castillo B, Cufí S, Del Barco S, Lopez-Bonet E, Brunet J and Menendez JA: Dynamic emergence of the mesenchymal CD44(pos)CD24(neg/ low) phenotype in HER2-gene amplified breast cancer cells with de novo resistance to trastuzumab (Herceptin). Biochem Biophys Res Commun 397: 27-33, 2010. 
19. Menendez JA, Vazquez-Martin A, Colomer R, Brunet J, Carrasco-Pancorbo A, Garcia-Villalba R, Fernandez-Gutierrez A and Segura-Carretero A: Olive oil's bitter principle reverses acquired autoresistance to trastuzumab (Herceptin) in HER2overexpressing breast cancer cells. BMC Cancer 7: 80, 2007.

20. Menendez JA, Vazquez-Martin A, Oliveras-Ferraros C, GarciaVillalba R, Carrasco-Pancorbo A, Fernandez-Gutierrez A and Segura-Carretero A: Extra-virgin olive oil polyphenols inhibit HER2 (erbB-2)-induced malignant transformation in human breast epithelial cells: relationship between the chemical structures of extra-virgin olive oil secoiridoids and lignans and their inhibitory activities on the tyrosine kinase activity of HER2. Int J Oncol 34: 43-51, 2009.

21. Menendez JA, Vazquez-Martin A, Garcia-Villalba R, CarrascoPancorbo A, Oliveras-Ferraros C, Fernandez-Gutierrez A and Segura-Carretero A: Anti-HER2 (erbB-2) oncogene effects of phenolic compounds directly isolated from commercial extravirgin olive oil (EVOO). BMC Cancer 8: 377, 2008.

22. García-Villalba R, Carrasco-Pancorbo A, Oliveras-Ferraros C Vázquez-Martín A, Menéndez JA, Segura-Carretero A and Fernández-Gutiérrez A: Characterization and quantification of phenolic compounds of extra-virgin olive oils with anticancer properties by a rapid and resolutive LC-ESI-TOF MS method. J Pharm Biomed Anal 51: 416-429, 2010.

23. Jensen SR, Franzyk H and Wallander E: Chemotaxonomy of the Oleaceae: iridoids as taxonomic markers. Phytochemistry 60 213-231, 2002.

24. Bendini A, Cerretani L, Carrasco-Pancorbo A, Gómez-Caravaca AM, Segura-Carretero A, Fernández-Gutiérrez A and Lercker G: Phenolic molecules in virgin olive oils: a survey of their sensory properties, health effects, antioxidant activity and analytical methods. An overview of the last decade. Molecules 12: 1679-1719, 2007.

25. Obied HK, Prenzler PD, Ryan D, Servili M, Taticchi A, Esposto S and Robards K: Biosynthesis and biotransformations of phenolconjugated oleosidic secoiridoids from Olea europaea L. Nat Prod Rep 25: 1167-1179, 2008.

26. Liebermann DA and Hoffman B: Gadd45 in stress signaling. J Mol Signal 3: 15, 2008

27. Cretu A, Sha X, Tront J, Hoffman B and Liebermann DA: Stress sensor Gadd45 genes as therapeutic targets in cancer. Cancer Ther 7: 268-276, 2009.

28. Wang XW, Zhan Q, Coursen JD, Khan MA, Kontny HU, Yu L, Hollander MC, O'Connor PM, Fornace AJ Jr and Harris CC: GADD45 induction of a G2/M cell cycle checkpoint. Proc Natl Acad Sci USA 96: 3706-3711, 1999.

29. Jin S, Tong T, Fan W, Fan F, Antinore MJ, Zhu X, Mazzacurati L, Li X, Petrik KL, Rajasekaran B, Wu M and Zhan Q: GADD45induced cell cycle G2-M arrest associates with altered subcellular distribution of cyclin $\mathrm{B} 1$ and is independent of p38 kinase activity. Oncogene 21: 8696-8704, 2002.

30. Zubia A, Ropero S, Otaegui D, Ballestar E, Fraga MF, BoixChornet M, Berdasco M, Martinez A, Coll-Mulet L, Gil J, Cossío FP and Esteller M: Identification of $(1 \mathrm{H})$-pyrroles as histone deacetylase inhibitors with antitumoral activity. Oncogene 28: 1477-1484, 2009.

31. Carrasco-Pancorbo A, Neususs C, Pelzing M, Segura-Carretero A and Fernandez-Gutierrez A: CE-and HPLC-TOF-MS for the characterization of phenolic compounds in olive oil.Electrophoresis 28: 806-821, 2007.

32. Singleton VL and Rossi JA: Colorimetry of total phenolics with phophomolybdic-phosphotungstic acid reagent. Am J Enol Vitic 16: $144-158,1956$

33. Hsu CL and Yen GC: Phenolic compounds: evidence for inhibitory effects against obesity and their underlying molecular signaling mechanisms. Mol Nutr Food Res 52: 53-61, 2008.

34. Crozier A, Jaganath IB and Clifford MN: Dietary phenolics: chemistry, bioavailability and effects on health. Nat Prod Rep 26: 1001-1043, 2009

35. Cicerale S, Conlan XA, Sinclair AJ and Keast RS: Chemistry and health of olive oil phenolics. Crit Rev Food Sci Nutr 49: 218-236, 2009.

36. Colomer R and Menéndez JA: Mediterranean diet, olive oil and cancer. Clin Transl Oncol 8: 15-21, 2006.

37. Menendez JA and Lupu R: Mediterranean dietary traditions for the molecular treatment of human cancer: anti-oncogenic actions of the main olive oil's monounsaturated fatty acid oleic acid (18:1n-9). Curr Pharm Biotechnol 7: 495-502, 2006.

38. Escrich E, Moral R, Grau L, Costa I and Solanas M: Molecular mechanisms of the effects of olive oil and other dietary lipids on cancer. Mol Nutr Food Res 51: 1279-1292, 2007.
39. Colomer R, Lupu R, Papadimitropoulou A, Vellón L, VázquezMartín A, Brunet J, Fernández-Gutiérrez A, Segura-Carretero A and Menéndez JA: Giacomo Castelvetro's salads. Anti-HER2 oncogene nutraceuticals since the 17th century? Clin Trans Oncol 10: 30-34, 2008.

40. Escrich E, Solanas M, Moral R, Costa I and Grau L: Are the olive oil and other dietary lipids related to cancer? Experimental evidence. Clin Transl Oncol 8: 868-883, 2006.

41. Galli C and Visioli F: Antioxidant and other activities of phenolics in olives/olive oil, typical components of the Mediterranean diet. Lipids 34: 23-26, 1999.

42. Owen RW, Giacosa A, Hull WE, Haubner R, Spiegelhalder B and Bartsch $\mathrm{H}$ : The antioxidant/anticancer potential of phenolic compounds isolated from olive oil. Eur J Cancer 36: 1235-1147, 2000.

43. Owen RW, Mier W, Giacosa A, Hull WE, Spiegelhalder B and Bartsch H: Identification of lignans as major components in the phenolic fraction of olive oil. Clin Chem 46: 976-988, 2000.

44. Visioli F and Galli C: Phenolics from olive oil and its waste products. Biological activities in in vitro and in vivo studies. World Rev Nutr Diet 88: 233-237, 2001.

45. Visioli F, Poli A and Galli C: Antioxidant and other biological activities of phenols from olives and olive oil. Med Res Rev 22: 65-75, 2002.

46. Visioli F and Galli C: Biological properties of olive oil phytochemicals. Crit Rev Food Sci Nutr 42: 209-221, 2002.

47. Beauchamp GK, Keast RS, Morel D, Lin J, Pika J, Han Q, Lee CH, Smith AB and Breslin PA: Phytochemistry: ibuprofen-like activity in extra-virgin olive oil. Nature 437: 45-46, 2005

48. Owen RW, Giacosa A, Hull WE, Haubner R, Würtele G Spiegelhalder B and Bartsch H: Olive-oil consumption and health: the possible role of antioxidants. Lancet Oncol 1: 107-112, 2000

49. Servili M, Esposto S, Fabiani R, Urbani S, Taticchi A, Mariucci F, Selvaggini R and Montedoro GF: Phenolic compounds in olive oil: antioxidant, health and organoleptic activities according to their chemical structure. Inflammopharmacology 17: 76-84, 2009.

50. Raederstorff D: Antioxidant activity of olive polyphenols in humans: a review. Int J Vitam Nutr Res 79: 152-165, 2009.

51. Sinclair DA: Toward a unified theory of caloric restriction and longevity regulation. Mech Ageing Dev 126: 987-1002, 2005.

52. Howitz KT and Sinclair DA: Xenohormesis: sensing the chemical cues of other species. Cell 133: 387-391, 2008.

53. Way TD, Kao MC and Lin JK: Apigenin induces apoptosis through proteasomal degradation of HER2/neu in HER2/neuoverexpressing breast cancer cells via the phosphatidylinositol 3-kinase/Akt-dependent pathway. J Biol Chem 279: 4479-4489, 2004.

54. Way TD, Kao MC and Lin JK: Degradation of HER2/neu by apigenin induces apoptosis through cytochrome $\mathrm{c}$ release and caspase-3 activation in HER 2/neuoverexpressing breast cancer cells. FEBS Lett 579: 145-152, 2005 .

55. Shimizu M, Deguchi A, Joe AK, Mckoy JF, Moriwaki H and Weinstein IB: EGCG inhibits activation of HER 3 and expression of cyclooxygenase-2 in human colon cancer cells. J Exp Ther Oncol 5: 69-78, 2005.

56. Shimizu M, Deguchi A, Hara Y, Moriwaki H and Weinstein IB: EGCG inhibits activation of the insulin-like growth factor-1 receptor in human colon cancer cells. Biochem Biophys Res Commun 334: 947-953, 2005.

57. Shimizu M, Deguchi A, Lim JT, Moriwaki H, Kopelovich L and Weinstein IB: (-)-Epigallocatechin gallate and polyphenon $\mathrm{E}$ inhibit growth and activation of the epidermal growth factor receptor and human epidermal growth factor receptor-2 signaling pathways in human colon cancer cells. Clin Cancer Res 11: 2735-2746, 2005

58. Chiang CT, Way TD and Lin JK: Sensitizing HER2-overexpressing cancer cells to luteolin-induced apoptosis through suppressing p21WAF1/CIP1 expression with rapamycin. Mol Cancer Ther 6: 2127-2138, 2007.

59. Baselga J, Albanell J, Molina MA and Arribas J: Mechanism of action of trastuzumab and scientific update. Semin Oncol 28: 4-11, 2001.

60. Molina MA, Codony-Servat J, Albanell J, Rojo F, Arribas J and Baselga J: Trastuzumab (herceptin), a humanized anti-Her2 receptor monoclonal antibody, inhibits basal and activated Her2 ectodomain cleavage in breast cancer cells. Cancer Res 61: 4744-4749, 2001 
61. O'Brien NA, Browne BC, Chow L, Wang Y, Ginther C, Arboleda J, Duffy MJ, Crown J, O'Donovan N and Slamon DJ: Activated Phosphoinositide 3-Kinase/AKT Signaling Confers Resistance to Trastuzumab but not Lapatinib. Mol Cancer Ther 9: 1489-1502, 2010.

62. Weiss RH: $\mathrm{p} 21^{\mathrm{Waf} 1 / \mathrm{Cipl}}$ as a therapeutic target in breast and other cancers. Cancer Cell 4: 425-429, 2003.

63. Guo H, Tian T, Nan K and Wang W: p57: $\alpha$ multifunctional protein in cancer (Review). Int J Oncol 36: 1321-1329, 2010.

64. Yu J and Zhang L: The transcriptional targets of p53 in apoptosis control. Biochem Biophys Res Commun 331: 851-858, 2005.

65. Ploner C, Kofler R and Villunger A: Noxa: at the tip of the balance between life and death. Oncogene 27 (Suppl. 1): S84-S92, 2008.

66. Mork CN, Faller DV and Spanjaard R: A mechanistic approach to anticancer therapy: targeting the cell cycle with histone deacetylase inhibitors. Curr Pharm Des 11: 1091-1104, 2005.

67. Ocker M and Schneider-Stock R: Histone deacetylase inhibitors: signalling towards $\mathrm{p} 21^{\text {cip } 1 / \text { waf } 1}$. Int J Biochem Cell Biol 39 1367-1374, 2007

68. Martínez-Iglesias O, Ruiz-Llorente L, Sánchez-Martínez R, García L, Zambrano A and Aranda A: Histone deacetylase inhibitors: mechanism of action and therapeutic use in cancer. Clin Transl Oncol 10: 395-398, 2008

69. Sowa Y, Orita T, Hiranabe-Minamikawa S, Nakano K, Mizuno T, Nomura $\mathrm{H}$ and Sakai T: Histone deacetylase inhibitor activates the $\mathrm{p} 21 / \mathrm{WAF} 1 / \mathrm{Cip} 1$ gene promoter through the Sp1 sites. Ann NY Acad Sci 886: 195-199, 1999.

70. Yokota T, Matsuzaki Y, Miyazawa K, Zindy F, Roussel MF and Sakai T: Histone deacetylase inhibitors activate INK4d gene through Sp1 site in its promoter. Oncogene 23: 5340-5349, 2004

71. Cucciolla V, Borriello A, Criscuolo M, Sinisi AA, Bencivenga D, Tramontano A, Scudieri AC, Oliva A, Zappia V and Della Ragione F: Histone deacetylase inhibitors upregulate $\mathrm{p} 57^{\mathrm{Kip}}$ level by enhancing its expression through $\mathrm{Sp} 1$ transcription factor. Carcinogenesis 29: 560-577, 2008

72. Cai X, Zhai HX, Wang J, Forrester J, Qu H, Yin L, Lai CJ, Bao R and Qian C: Discovery of 7-(4-(3ethynylphenylamino)-7methoxyquinazolin-6-yloxy)-N-hydroxyheptanamide(CUDC101) as a potent multi-acting HDAC, EGFR, and HER2 inhibitor for the treatment of cancer. J Med Chem 3: 2000-2009, 2010.

73. Lai CJ, Bao R, Tao X, Wang J, Atoyan R, Qu H, Wang DG Yin L, Samson M, Forrester J, Zifcak B, Xu GX, DellaRocca S, Zhai HX, Cai X, Munger WE, Keegan M, Pepicelli CV and Qian C: CUDC-101, a multitargeted inhibitor of histone deacetylase, epidermal growth factor receptor, and human epidermal growth factor receptor 2 , exerts potent anticancer activity. Cancer Res 70: 3647-3656, 2010.

74. Bali P, Pranpat M, Swaby R, Fiskus W, Yamaguchi H, Balasis M, Rocha K, Wang HG, Richon V and Bhalla K: Activity of sub-eroylanilide hydroxamic Acid against human breast cancer cells with amplification of her-2. Clin Cancer Res 11: 6382-6389, 2005
75. Kültz D, Madhany S and Burg MB: Hyperosmolality causes growth arrest of murine kidney cells. Induction of GADD45 and GADD153 by osmosensing via stress-activated protein kinase 2 . J Biol Chem 273: 13645-13651, 1998.

76. Takekawa M and Saito H: A family of stress-inducible GADD45like proteins mediate activation of the stress-responsive MTK1/ MEKK4 MAPKKK. Cell 95: 521-530, 1998.

77. O'Prey J, Brown J, Fleming J and Harrison PR: Effects of dietary flavonoids on major signal transduction pathways in human epithelial cells. Biochem Pharmacol 66: 2075-2088, 2003.

78. Chi H,Lu B, Takekawa M, Davis RJ and Flavell RA: GADD45beta/ GADD45gamma and MEKK4 comprise a genetic pathway mediating STAT4-independent IFNgamma production in T cells. EMBO J 23: 1576-1586, 2004.

79. Bulavin DV, Kovalsky O, Hollander MC and Fornace AJ Jr: Loss of oncogenic $\mathrm{H}$-rasinduced cell cycle arrest and p38 mitogenactivated protein kinase activation by disruption of Gadd45a. Mol Cell Biol 23: 3859-3871, 2003.

80. Wei GH, Zhao GW, Song W, Hao DL, Lv X, Liu DP and Liang CC: Mechanisms of human gamma-globin transcriptional induction by apicidin involves p38 signaling to chromatin. Biochem Biophys Res Commun 363: 889-894, 2007.

81. Zhao Q, Barakat BM, Qin S, Ray A, El-Mahdy MA, Wani G, Arafa el-S, Mir SN, Wang QE and Wani AA: The p38 mitogenactivated protein kinase augments nucleotide excision repair by mediating DDB2 degradation and chromatin relaxation. J Biol Chem 283: 32553-32561, 2008.

82. Seo SB, McNamara P, Heo S, Turner A, Lane WS and Chakravarti D: Regulation of histone acetylation and transcription by INHAT, a human cellular complex containing the set oncoprotein. Cell 104: 119-130, 2001

83. Saha RN,Jana M and Pahan K: MAPK p 38 regulates transcriptional activity of NF-kappaB in primary human astrocytes via acetylation of p65. J Immunol 179: 7101-7109, 2007.

84. Liu X, Wang L, Zhao K, Thompson PR, Hwang Y, Marmorstein R and Cole PA: The structural basis of protein acetylation by the p300/CBP transcriptional coactivator. Nature 451: 846-850, 2008.

85. Chavan P, Joshi K and Patwardhan B: DNA microarrays in herbal drug research. Evid Based Complement Alternat Med 3: 447-457, 2006

86. Wermuth CG: Multitargeted drugs: the end of the 'one-targetone-disease' philosophy? Drug Discov Today 9: 826-827, 2004.

87. Oliveras-Ferraros C, Vazquez-Martin A, Martin-Castilló B, Pérez-Martínez MC, Cufí S, Del Barco S, Bernado L, Brunet J, López-Bonet E and Menendez JA: Pathway-focused proteomic signatures in HER2-overexpressing breast cancer with a basallike phenotype: new insights into de novo resistance to trastuzumab (Herceptin). Int J Oncol 37: 669-678, 2010. 